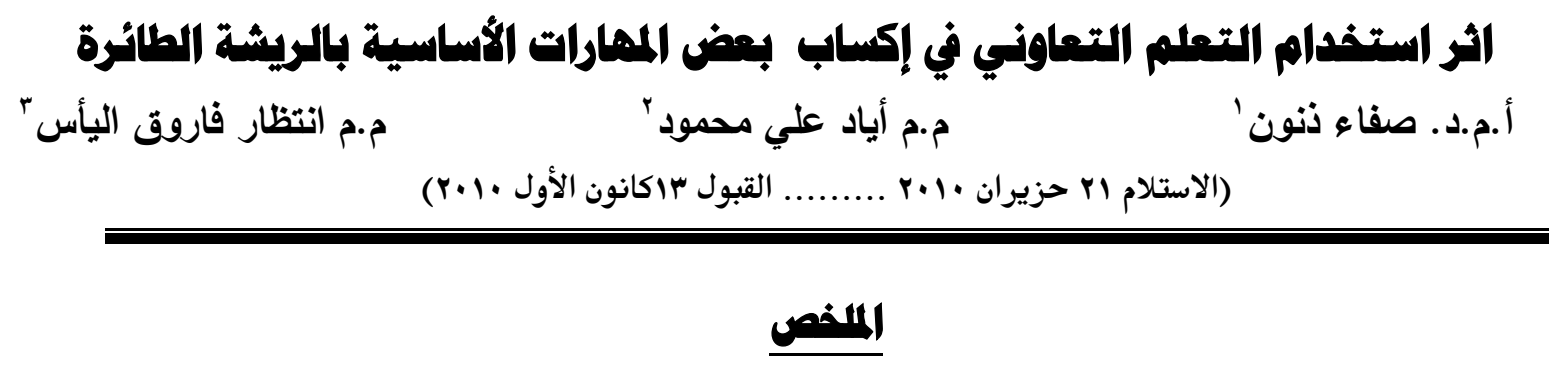

هاف البحث إلى التعرف على درجة اثر التعلم التعاوني في إكساب بعض المهارات الأساسية للعبة الريشة

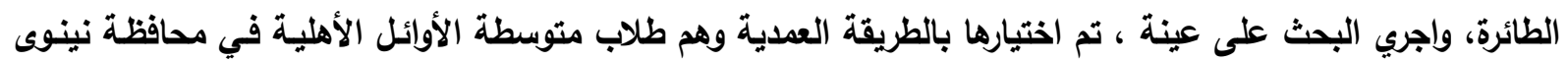

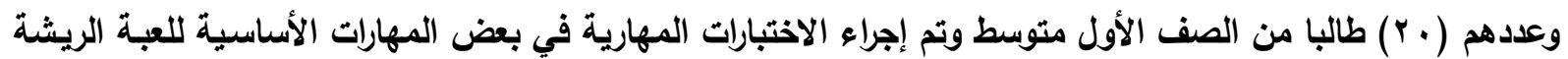

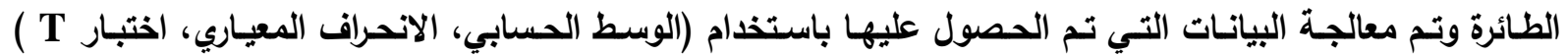
وأسفرت النتائج عن وجـود فروق ذات دلالـة معنويـة بين متوسطات درجـات طـلاب المجموعـة التجريبيـة وإلضابطة

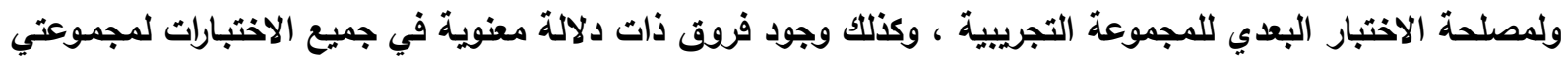
البحث في الاختبار البعدي ولمصلحة المجموعة التجريبية .

\title{
THE EFFECTE OF APPLYING COOPERATIVE LEARNING ON OBTAINING AND CERTAIN BASIC SKILLS OF BADMINTON SPORT
}

Asist.Prof.Safa'Th.Al'imam

Asist.Lecturer.Ayad.A.Mahmood

Asist.Lecturer.Intidhar.F.Ilyas

\section{$\underline{\text { Abstract }}$}

The research aimed at recognizing the effect extent of the cooperative learning technique on learning certain basic skills of Badminton game. The research was conducted on a sampIe intentionally chosen fram the of Alawa'il private intermediate school in Ninevah province consisted of (20) subjects from the $1^{\text {st }}$ intermediate class. Skillful tests regarding the basic skills of the Badminton game were performed and the data obtained by the researchers were handled by applying (standard deviation, arithmetic mean, and T-test).

Resullos have shown significant differences between students' mean grades of both the experimental and control groups (the first and the second) in favor of post-tests as well as significant differences in all tests of both research groups in post-test in favor of the first experimental group. therefore, researchers recommended that cooperative learning technique should be used in learning and obtaining certain basic skills in Badminton sport and other sports as well.

فرع الألعاب الفردية/كلية التربية الرياضية/جامعة الموصل/العراق. dr_safaalemam@yahoo.com `مديرية التربية الرياضية والفنية/كلية التربية الرياضية/جامعة الموصل/العراق. 'فرع الألعاب الفرقية/كلية التربية الرياضية/جامعة الموصل/العراق. 
في بداية الألفية الثالثة وجد المعنيون في مجال طرائق التدريس ضرورة استخدام أساليب حديثة في التعلم

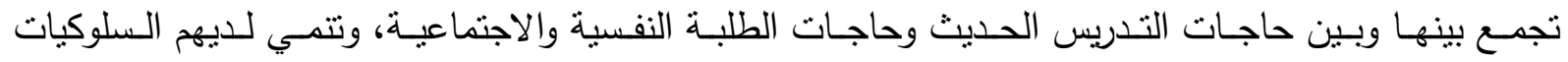

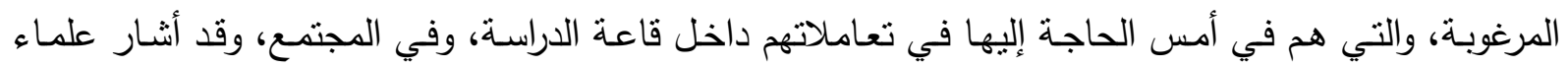

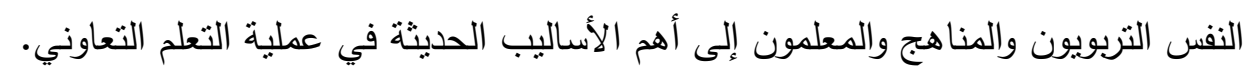

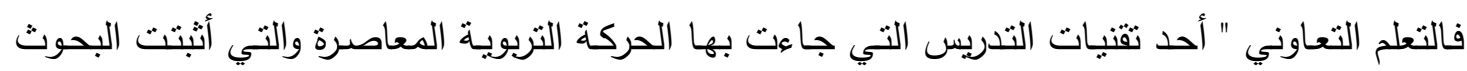

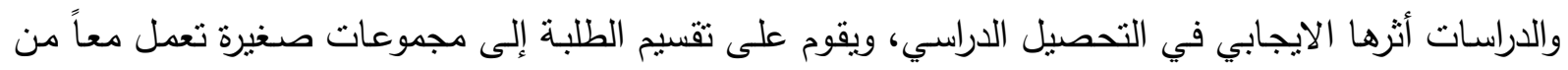

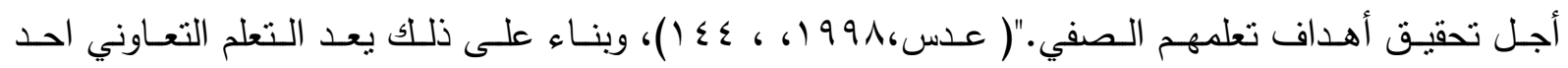

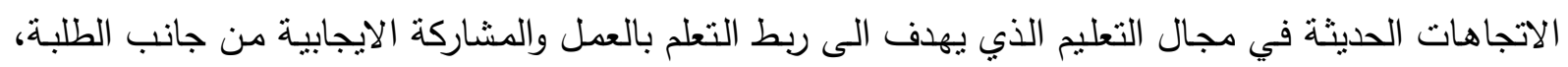

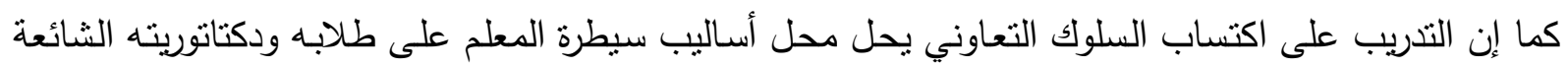

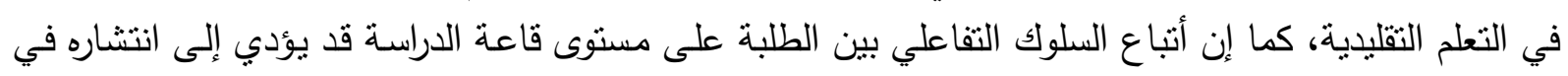

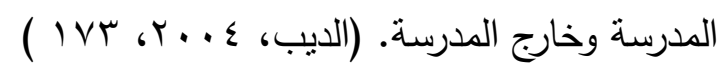

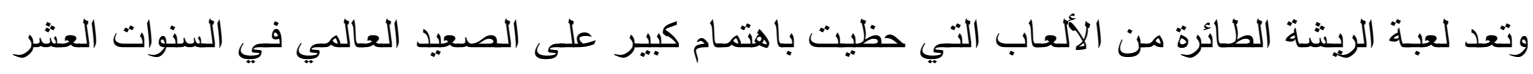

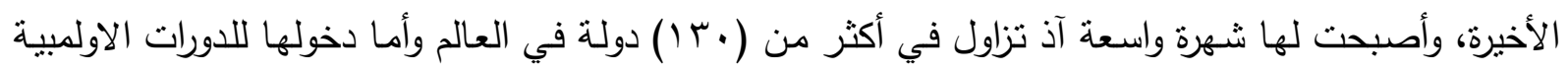

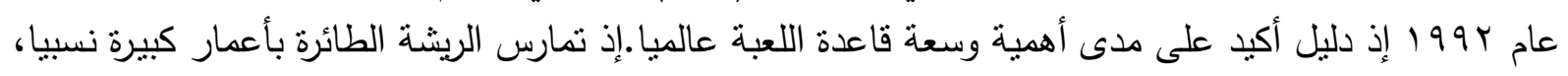

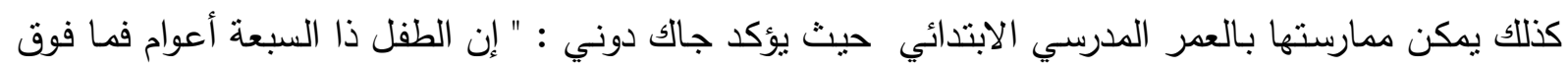

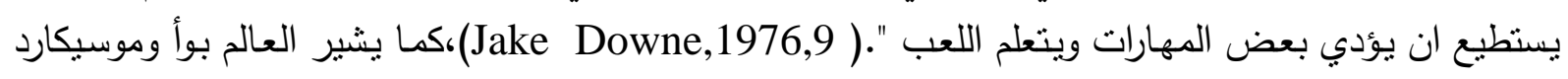

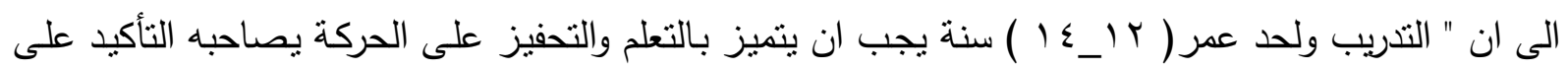

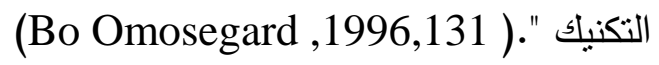

وتأتي أهميـة البحث إلى دراسـة توضـح فاعليـة التعلم التعاوني في إكساب بعض المهارات الأساسية

$$
\text { بالريشة الطائرة لعينة من المبتئئين. }
$$

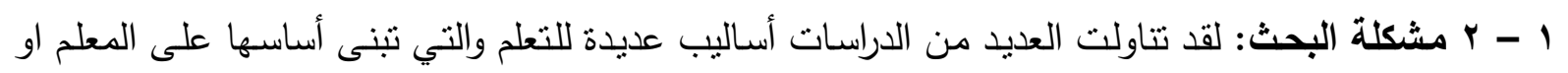

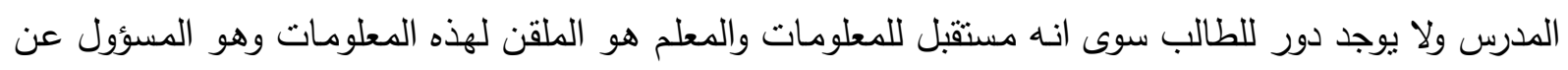

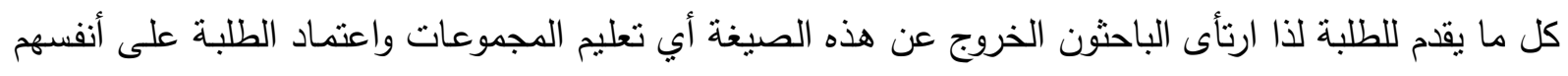

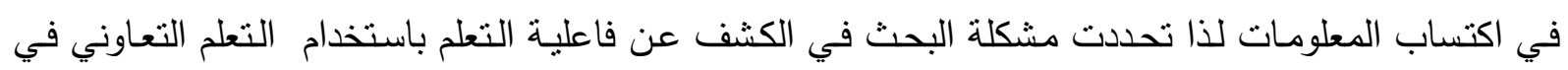
إكساب بعض المهارات الأساسية بالريثة الطائرة.

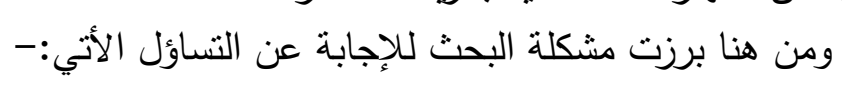

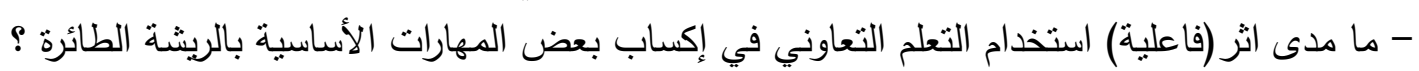

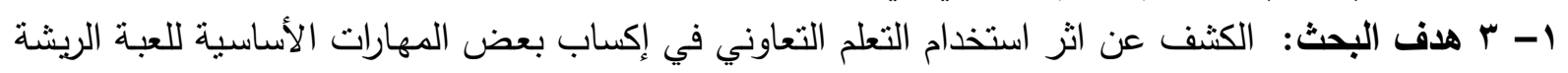
الطائرة 1- ؛ فرض البحث: توجد فروق ذات دلالة إحصائية بين مجموعتي البحث ( التجريبية والضابطة ) ولمصلحة

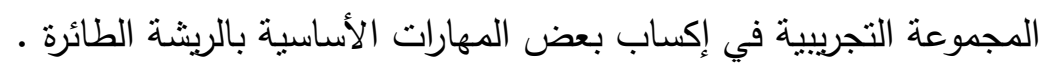

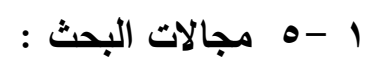
1

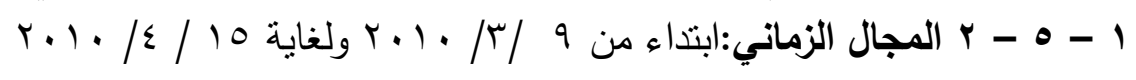

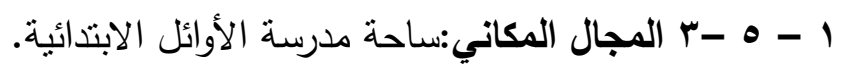




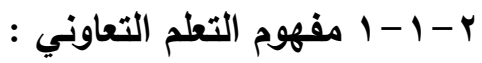

التعلم التعاوني من الأساليب الحديثة التي تهدف الى تحسين وتتشيط أفكار الطلاب الذين يعملون في

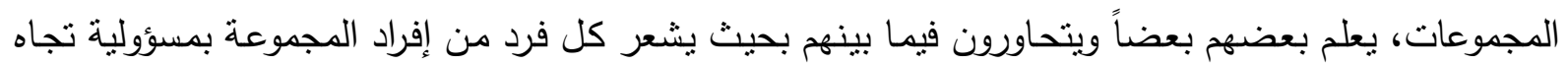

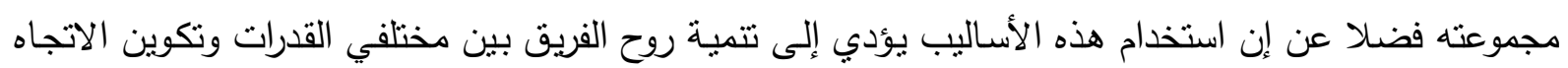

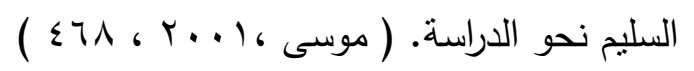

وبهذا يعترف التعليم الحديث بالفروقات الفردية القائمة بين الطلاب ، ويواجه الاهتمام لمراعاتها بمختلف

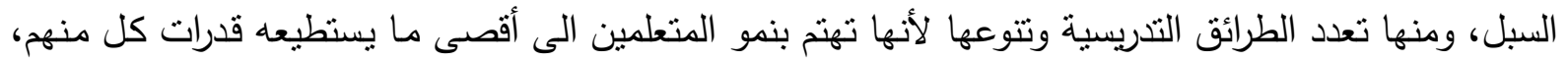

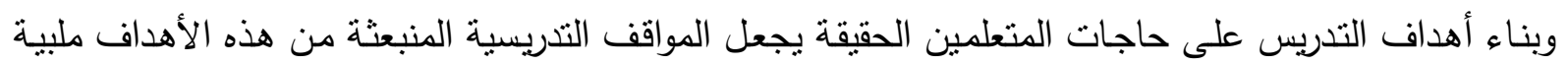

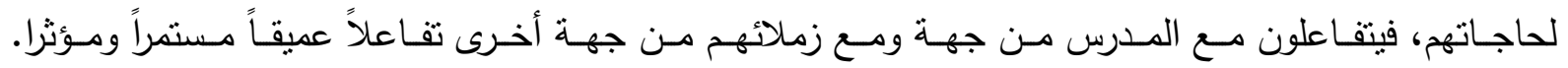

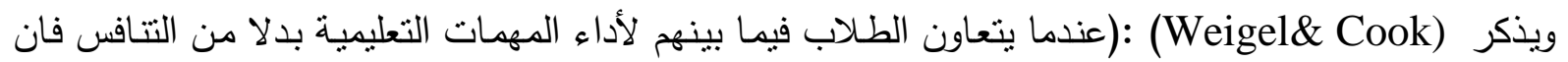

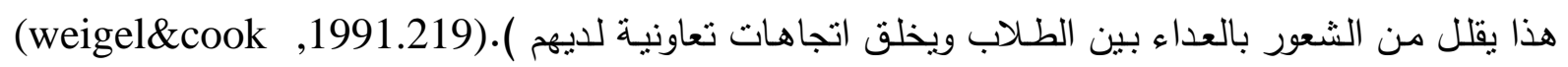

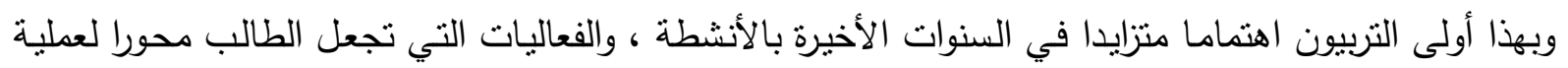

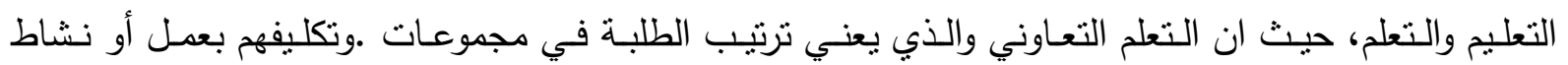

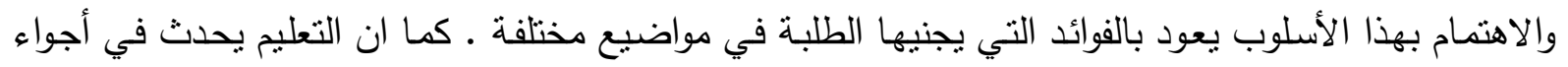

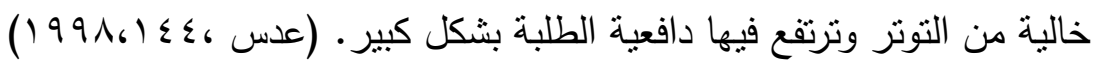

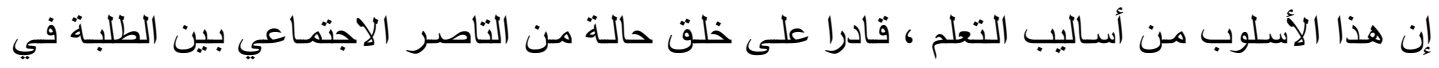

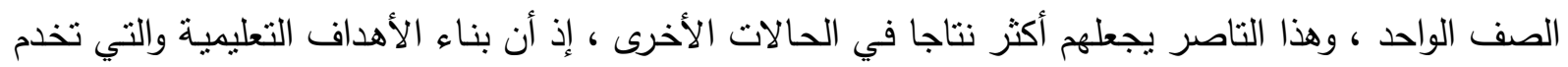

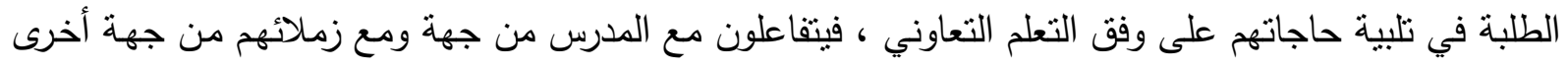

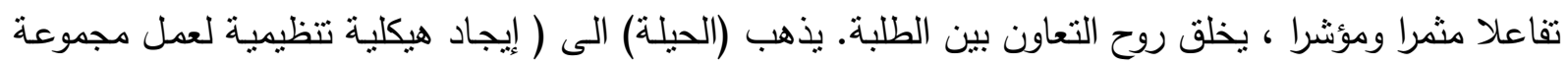

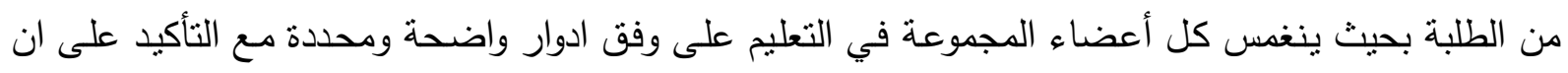

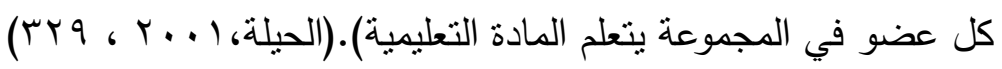
r-1 r- العوامل التي تسهم في نجاح أسلوب التعلم التعاوني:

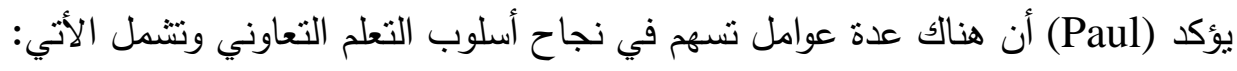
• شعور الفرد باتجاه مجموعته التي يعمل معها لتحقيق المهمة الرئيسة بالألفة والانسجام.

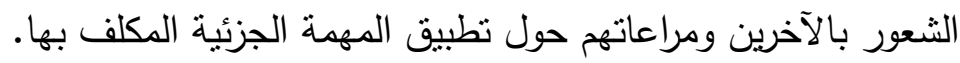

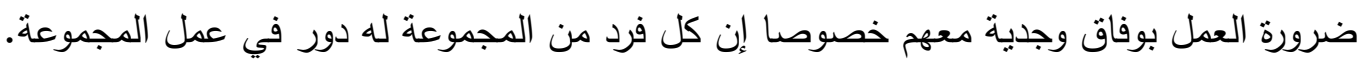
وضوح أهداف التعلم لطلبة الجموعة الواحدة. توزيع المهمات والواجبات وتنظيم موقع لعمل المجموعات. لكي يكون التعلم تعاونيا حقيقيا يجب إن يتضمن المبادئ الخمسة الأساسية في تعلم المجموعات. (Paul,1988,p20) r - 1 - r مهارات لعبة الريثة الطائرة : إن من الواجبات المعلم (المدرب) هو تعليم المهارات الأساسية للعبة

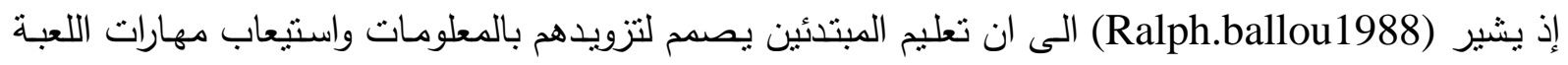
الأساسية والقابلية على انجازها بأفضل صورة.(Ralph,1988,26) 
ومن المتفق عليه ان نجاح أي لاعب يتوقف على العهى مدى إجادته للمبادئ الأساسية وكلما تمكن من أداء

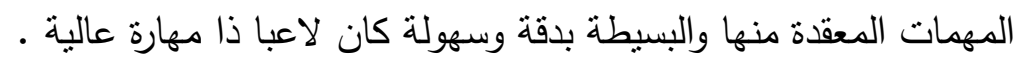
لقد اتفق كل من (john Edwards)\&(peter roper) على ان المهارات الأساسية للعبة الريشة الطائرة تتضمن ما يأني:

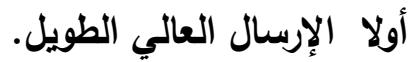

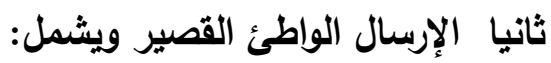

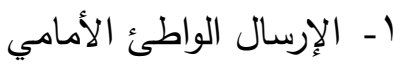

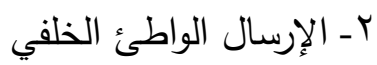

ثالثا الضريات الأمامية من فوق الرأس وتثشمل :

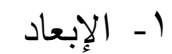

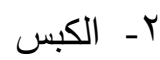

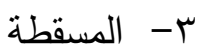

ارابعا الضريات الخلفية من فوق الرأس وتثثمل:

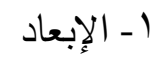

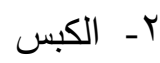

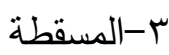

خامسا الضريات بمستوى الكتف وتثمل:

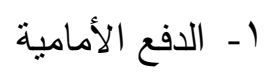

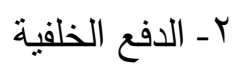

سادسا الضريات من الأسفل وتثمل : الأن

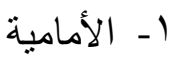

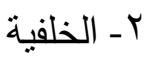

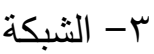

وفيما يأني شرح موجز للمهارات الأربع التي اختارها الباحثون في البحث :

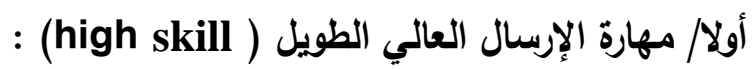

يعرف الإرسال بأنه ( عملية وضع الريشة في اللعب ويستلزم ضربات تحت مستوى الحزام وتفرض قوانين

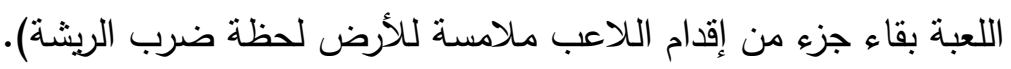

(Ralph B. Ballou. Op.cit.p.46)

كنلك يعرف الإرسال بأنه الرمية التي يبدأ بها اللعب سواء في أول المباراة وفي إعقاب نسجيل نقطة ،

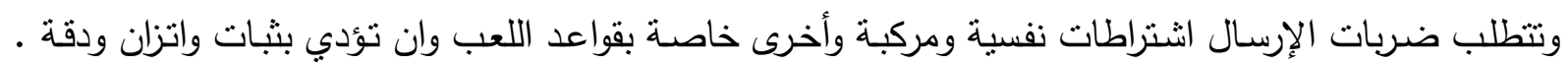

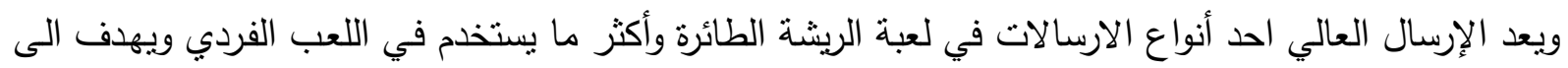

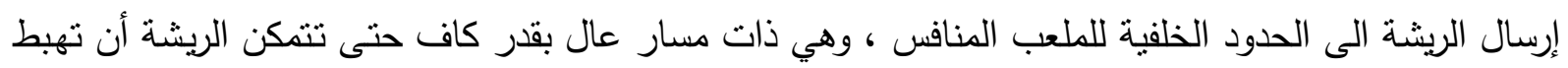
بشكل عمودي فوق النلاعب المستقبل تقريبا. 
ثانيا-مهارة الإرسال الواطئ (القصير) (The Short Low serve) :

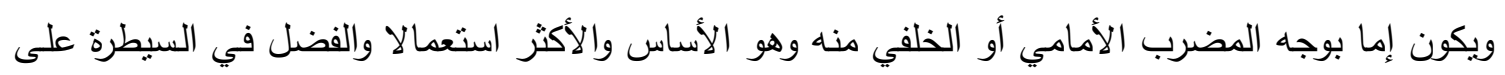

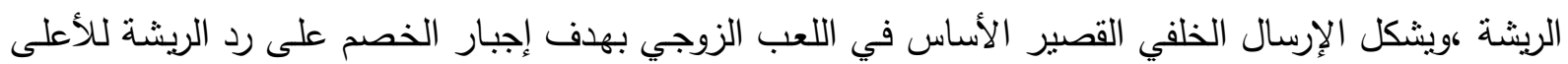
،ويتخذ المرسل وضعية الإرسال بوقوفه خلف خط الإرسال الأمامي مباشرة وقريبا من الخط الوسطي مستخدما لإسا

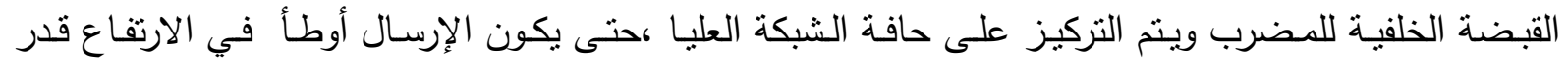

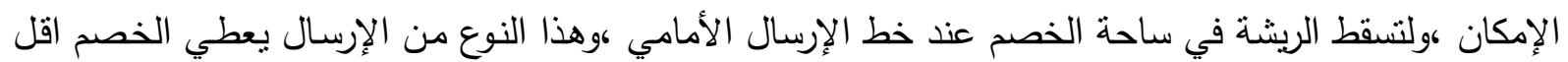

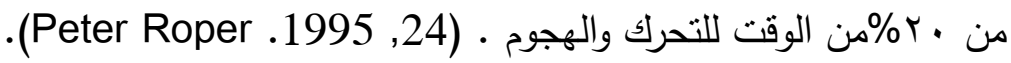
ثالثا/ مهارة الضرية الأمامية (من فوق الرأس) over head fore hand clear

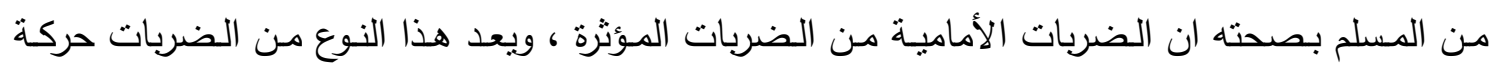

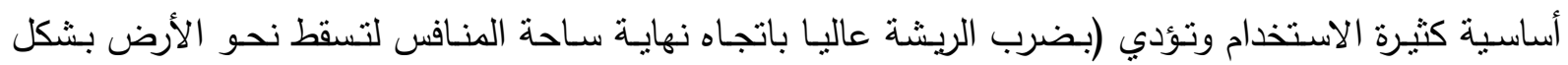

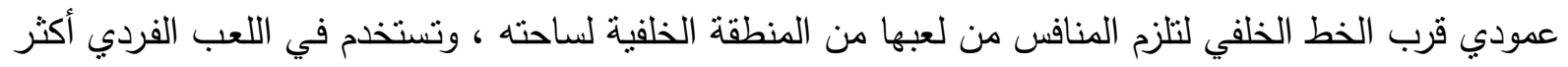
منها في اللعب الزوجي ).(Pete Roper. Op. cit . p.33)

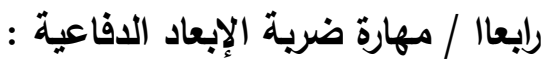
وهي من أكثر الضربات استخداما في لعبـة الريشة الطائرة ويشار إلى أنها نؤدى بالوجـه الأمـامي اوالخلفي

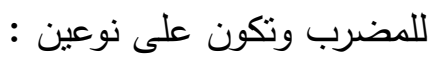
| أ - ضرية الإبعاد الدفاعية. وفيها ترسل الريشة عاليا وبعمق باتجاه ساحة المنافس ، وتصل الى أقصى ارتفاع لهاعل لها بصورة تقريبية

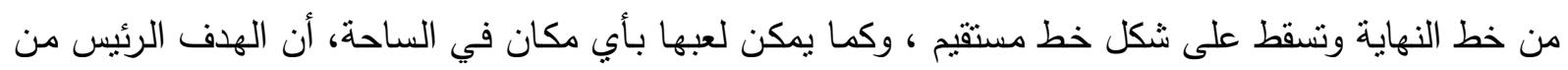
هذه الضربة هو لإتاحة الوقت للاعب للرجوع وتغطية الملعب ، ويحصل هذا قبل وصول الريشة الى منطقة

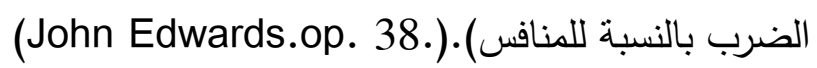
ب - مهارة ضرية الإبعاد الهجومية: وفيها تضرب الريشة بمسار منحني ضمل (قليل الإنحاد الهنداء وبارتفاع بحيث لاستطيع المنافس الوصول

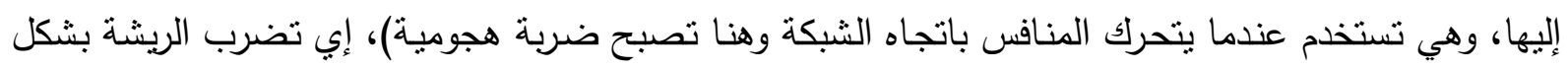
شبة مستقيم وسريع إلى المنطقة الخلفية الفارغة من الملعب . بعد الاطلاع على المصادر استخدم الباحثون تحليل المحتوى لاختيار الاختبارات المهارية للبحث وكما ياتي:

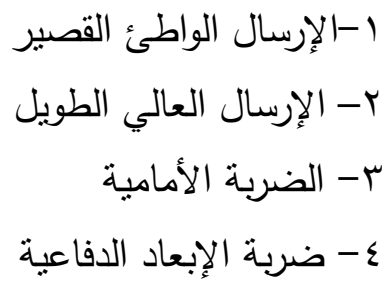




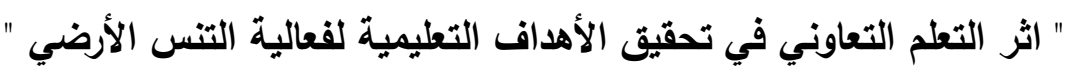

هدفت الدراسة إلى الكثف عن اثثر استخدام التعلم التعاوني:

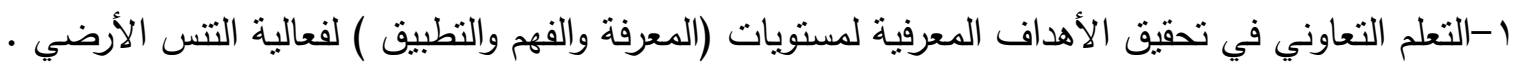

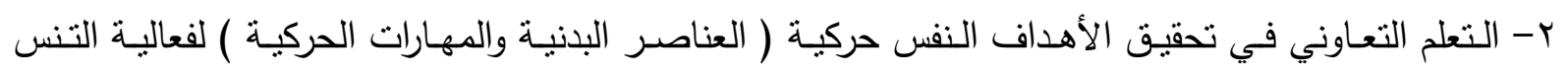

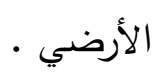
r- التعلم التعاوني في تحقيق الأهداف الانفعالية لفعالية التنس الأرضي ـ وللتحقق من أهداف البحث وضع

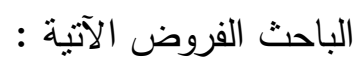
1- توجد فروق ذات دلالة إحصائية بين مجموعتي البحث (التعاونية والتقليدية ) في تحقيق الأهداف المعرفية

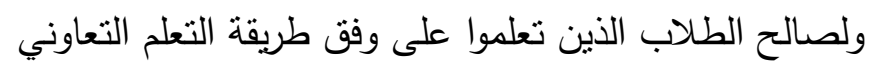

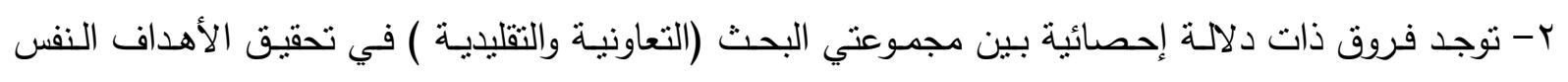

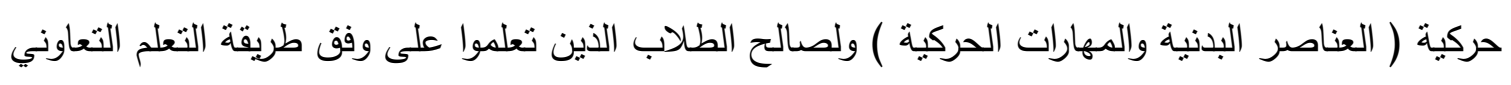

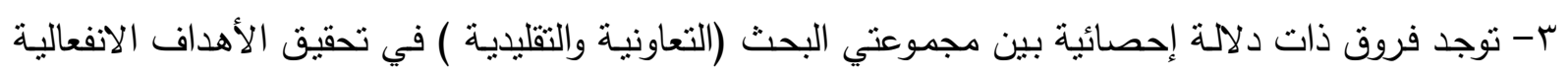

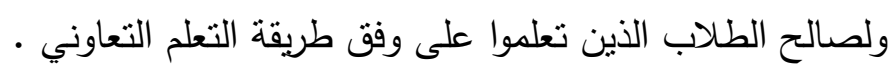

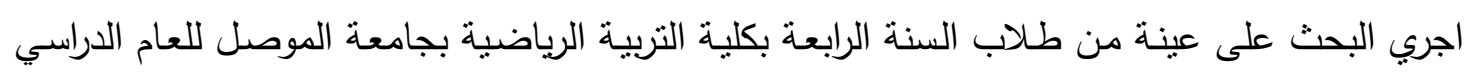

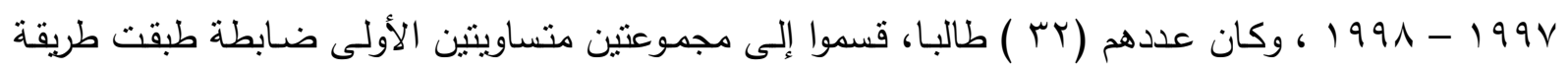

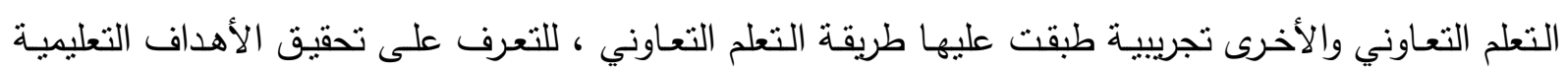

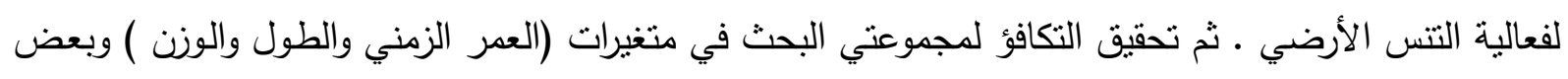

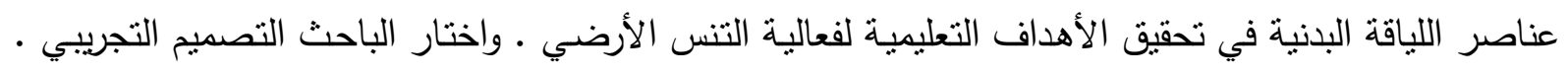

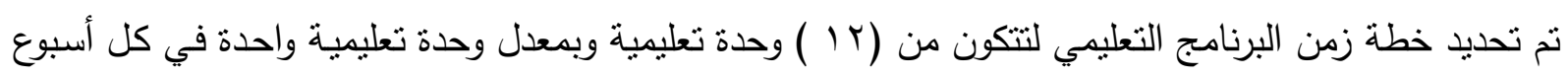

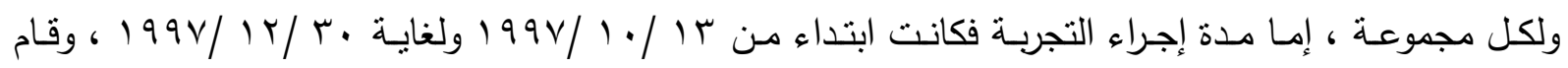

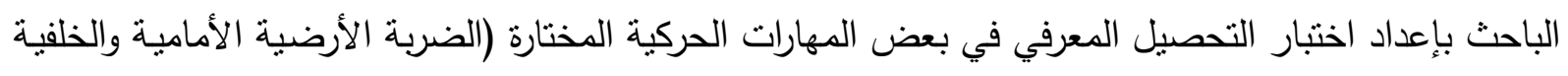

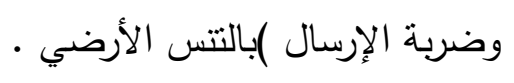

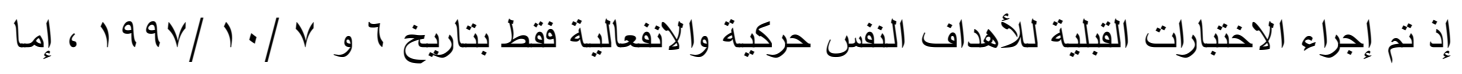

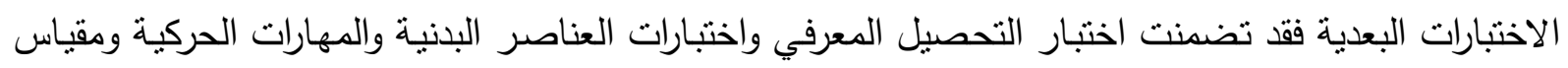

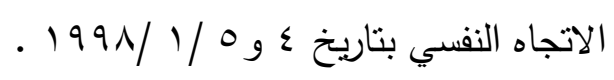
وبعد جمع البيانات وتفريغها عولجت إحصائيا باستخدام اختبار (ت ) للعينات المتساوية واختبار حجم الأثر

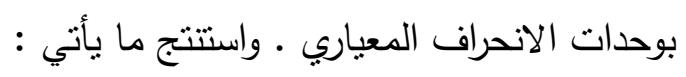

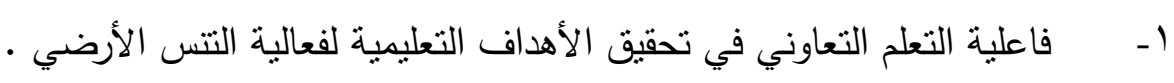

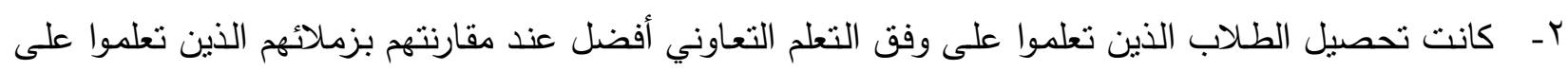
وفق التعلم التقليدي في تحقيق : أ - الأهداف المعرفية لمسنويات (المعرفة والفهم والنطبيق ) 
ب- الأهداف النفس حركية (العناصر البنية وابعابع في العهارات الحركية )

$$
\text { وأوصى الأهداف الانفعالية . }
$$

1- التأكبد على استخدام التعلم التعاوني بوصفة أفضل من النعلم التقليدي في تحقيق الأهداف التعليمية بالتس

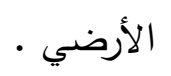

r- التأكبد على الأهداف الانفعالية التي تعمل على زيادة ممارسة الطلاب خارج الدرس ، ولما لها من تأثير في

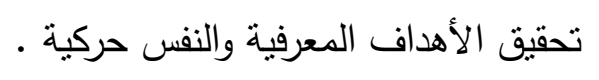

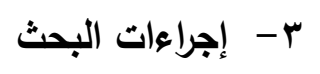

r-1 منهج البحث :استخدم المنهج التجريبي لملائمته طبيعة البحث ومشكلته .

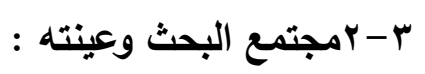

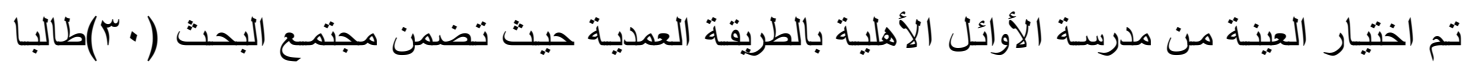

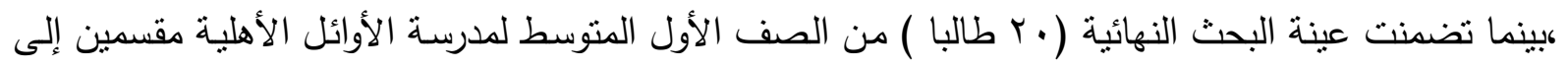

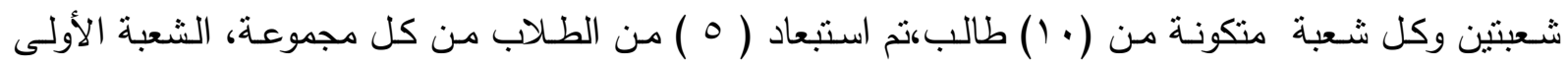

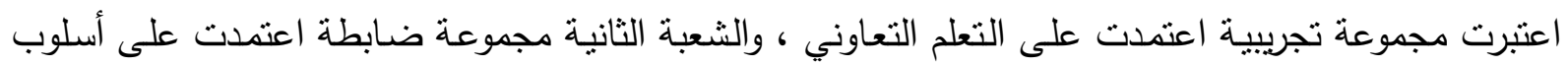

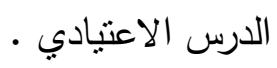

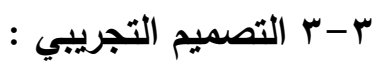

\begin{tabular}{|c|c|c|c|c|c|c|}
\hline \multirow{2}{*}{ قالمتسبة ت } & \multicolumn{2}{|c|}{ الضابطة } & \multicolumn{2}{|c|}{ التجريبية } & \multirow{2}{*}{ القياسة } & \multirow{2}{*}{ القياس } \\
\hline & $\varepsilon^{ \pm}$ & س & $\varepsilon^{ \pm}$ & س & & \\
\hline . & $1, r \vee \Lambda$ & $1 \leqslant 0, \ldots$ & $1, \varepsilon \leqslant \pi$ & $1 \leqslant 4, \leqslant$. & سم & الطول \\
\hline ., roY & $1, \times 4$ & $\{0,00$ & 1,70 & $\varepsilon 0, r \leqslant$ & كفم & الكتلة \\
\hline$\cdot, \leqslant 79$ &., $01 \mathrm{~V}$ & $10 \Lambda, \vee r$ & $\cdot, \leqslant \vee V$ & $10 V, 04$ & شهر & العمر \\
\hline 1,071 & r...r & 7.6 & $r_{6} \varepsilon$. & A.V & درجة & الإرسال الطويل \\
\hline $1, r q \wedge$ & $961+4$ & $1 \leq 69$ & $v_{c} \leqslant 0$ & $17 ، ؛$ & درجة & الإرسال القصير \\
\hline$\cdot, 99 \leq$ & \& & $11 ،$ & $r(0) \leqslant$ & $1 r .9$ & درجة & الضرية الأمامية \\
\hline$\cdot, \wedge \leqslant 9$ & T.rVA & $1 T, r$ & TITY) & $1 \leqslant$ & درجة & ضربة الإبعاد \\
\hline
\end{tabular}

تم استخدام التصميم التجريبـي (تصميم المجموعـات المتكافئـة ) العشتوائية الاختيـار ذات الملاحظــة القبليـة

والبعدية.

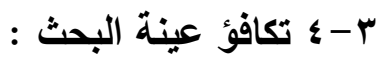

الجدول رقم(1) تكافؤ أفراد مجموعتي البحث في متغيرات الطول والكتلة والعمر ويعض المهارات الأساسية في الريشة الطائرة

من الجدول رقم (1) الخاص بقياس التكافؤ بين عينة البحث في القياس (الطول والكتلة والعمر وبعض المهارات

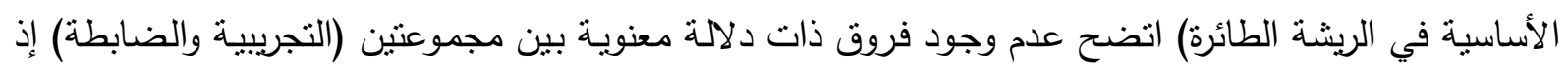




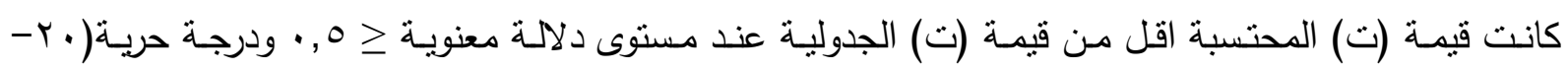

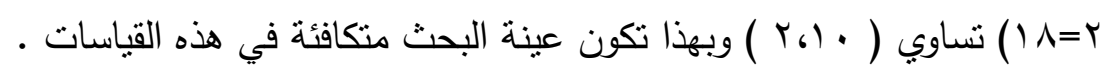

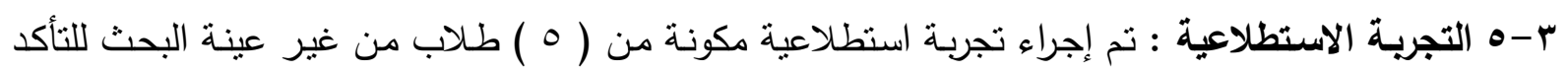
من صلاحية الساحة والأدوات ومدة الدرس .

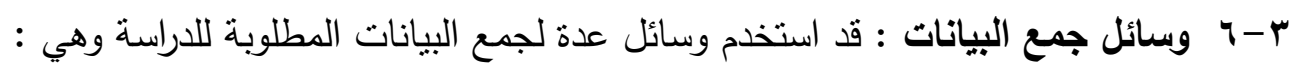
1- الاختبارات المهارية. r- استمارة الاستبيان الخاصة بمتغيرات البحث.

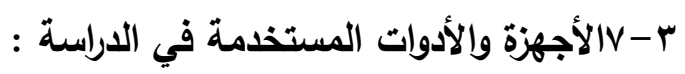

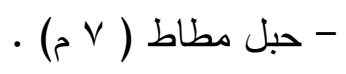

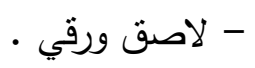

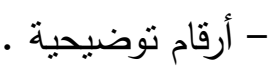

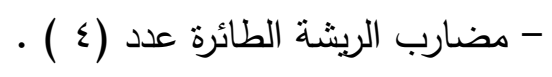

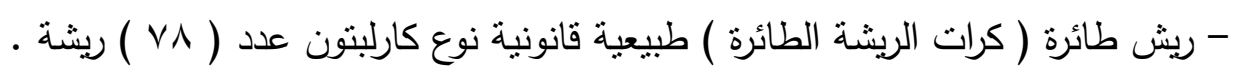

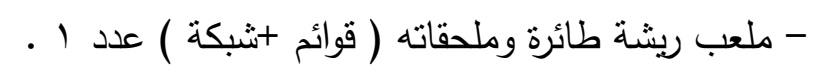
- قوائم إضافية مع أعمدة خشبية لازمة لعدد من الاختبارات المهارية .

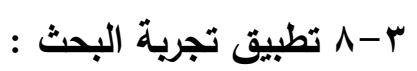

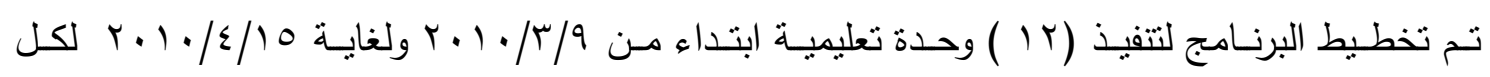

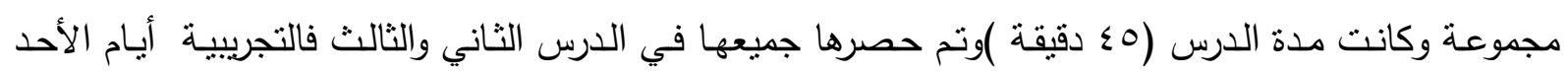

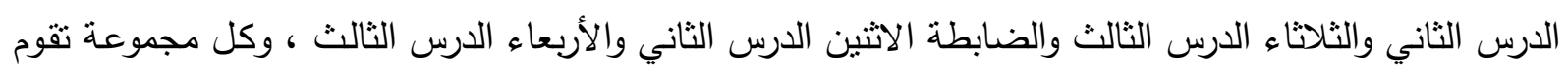

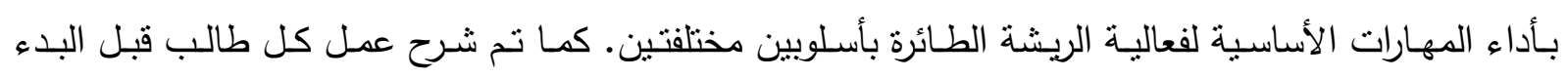

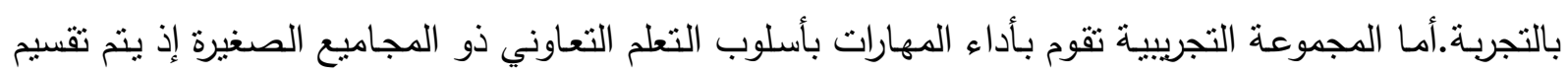

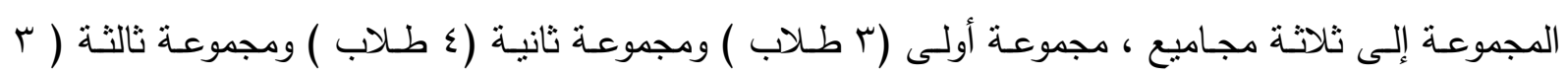

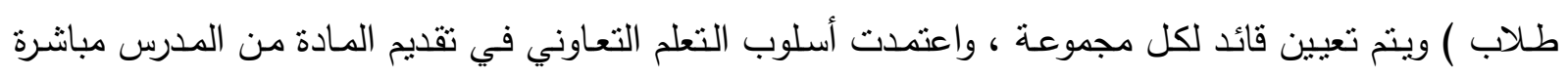

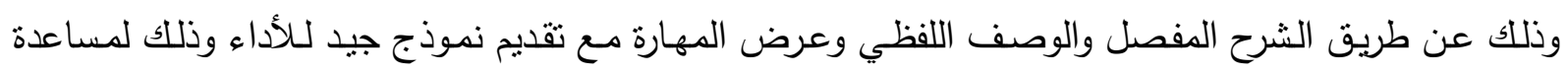

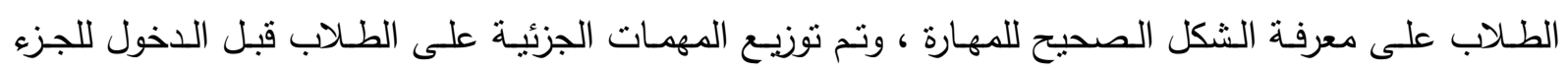

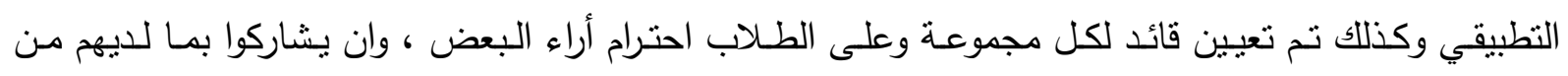

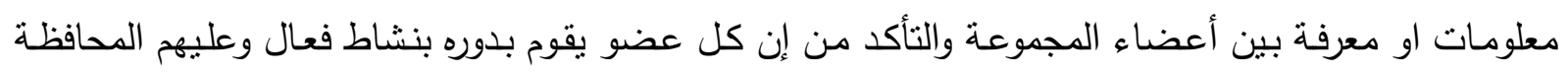

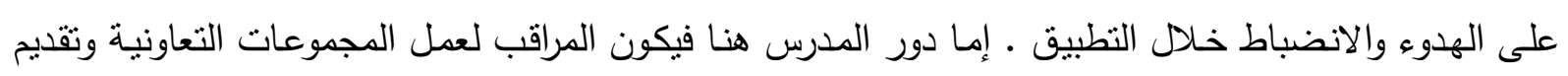
التغذية الراجعة لهم عن طريق القائد.

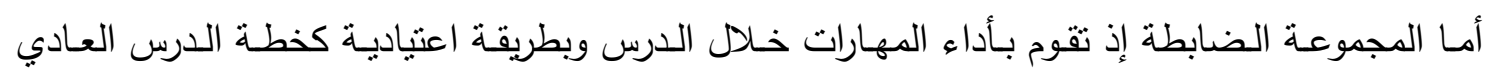

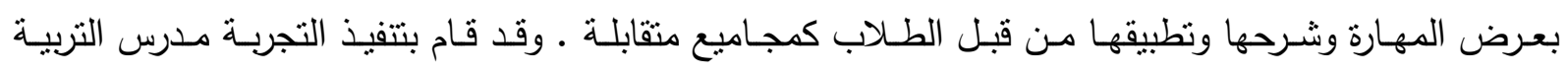

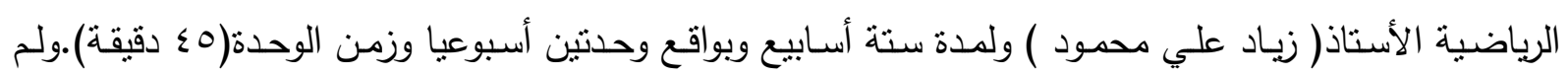
يدخل أي متغير خارجي يؤثر على سير التجربة. 
ب-9 الاختبارات القبلية والبعدية :

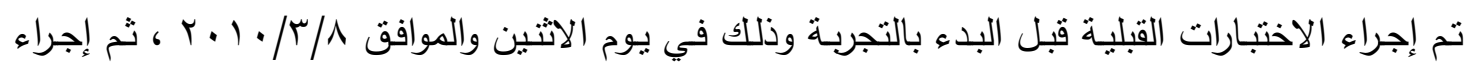

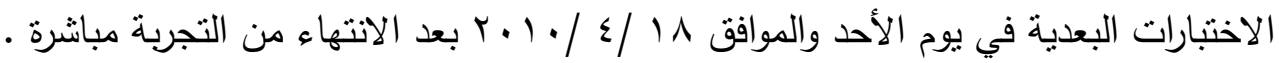

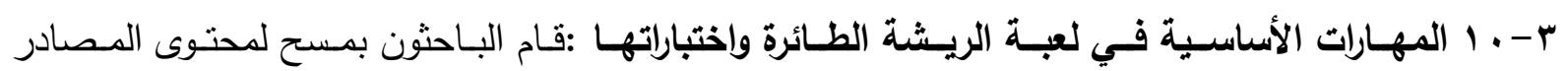

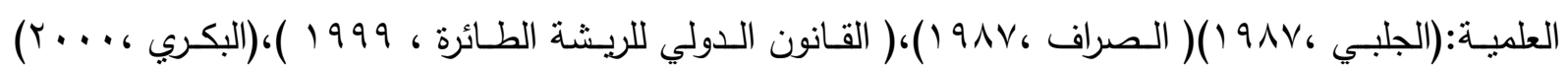

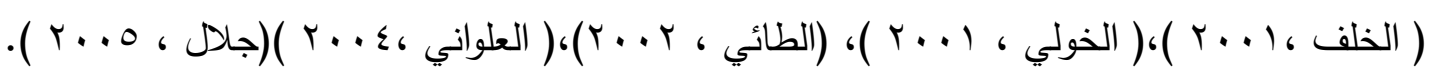

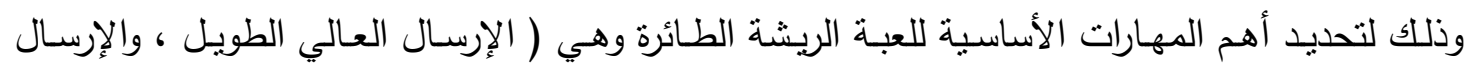

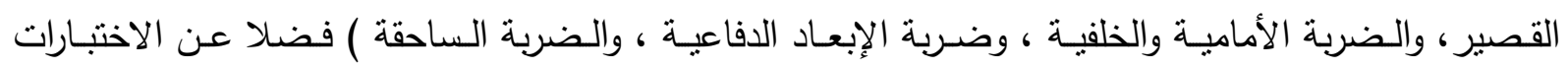

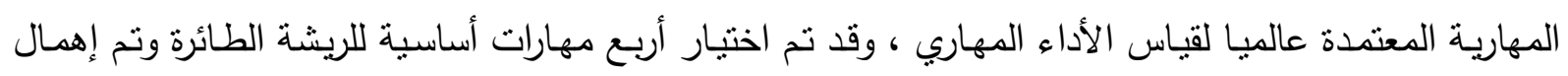

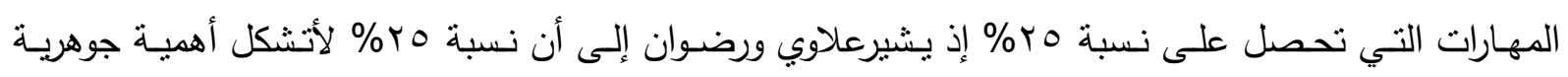

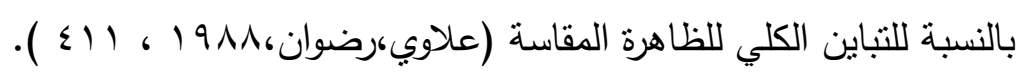

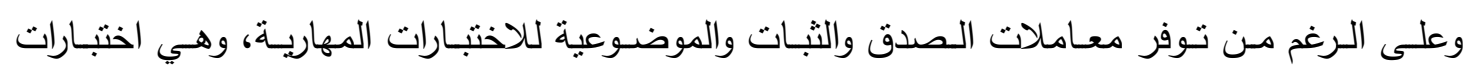

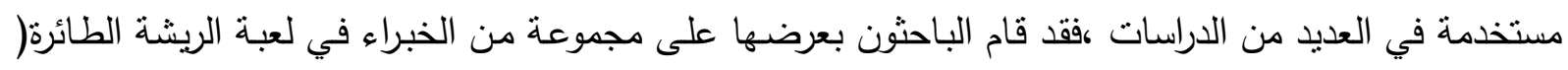

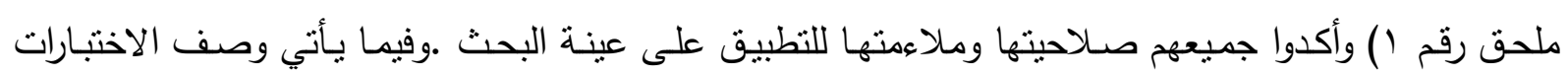
المهارية :

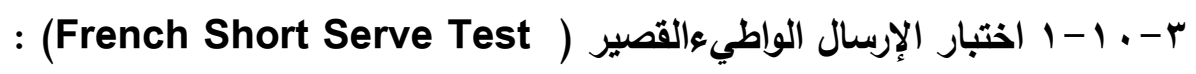
- هدف الاختبار : قياس الدقة لمهارة الإرسال القصير . - نطبيق الاختبار : طبق على عينة من طلاب المعاهد والكليات لكلا الجنسين .

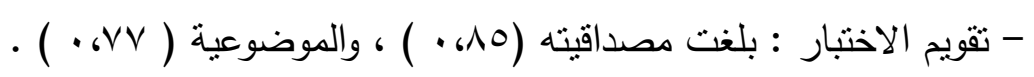

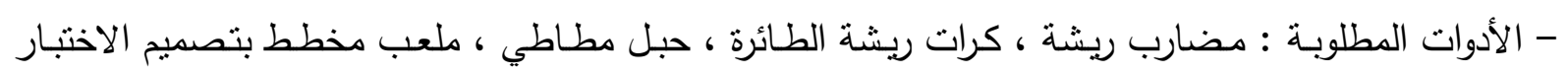

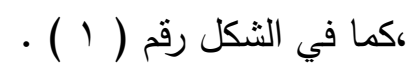

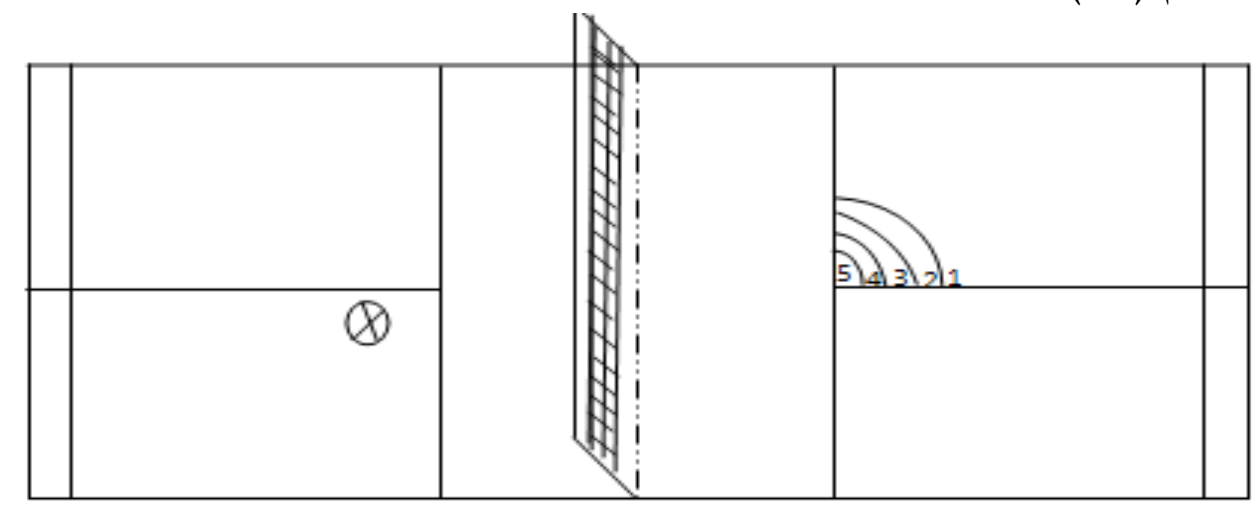

الثكل رقم ( 1 ) يوضح ملعب الريشة الطائرة مخطط بتصميم اختبار الإرسال القصير

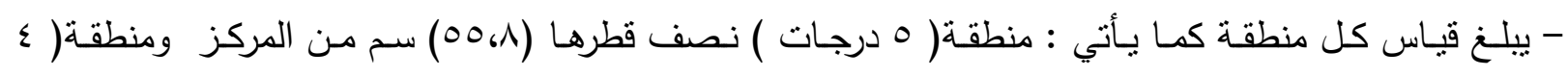

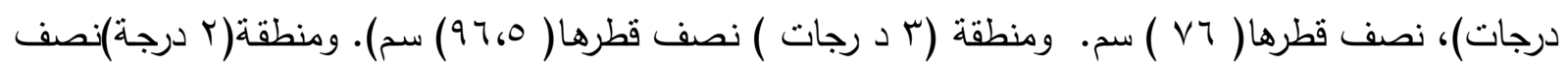

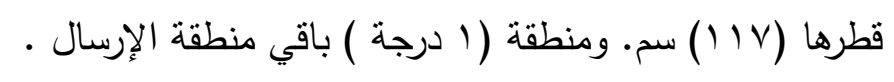

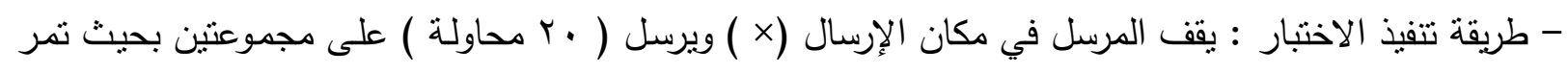

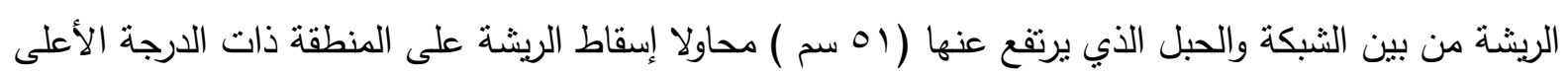


- حساب النقاط : تعطى الدرجة على وفق مكان سقوط الريشة ، الريشة التي تقع على خط بين منطقتين تعطى الدرجـة الأعلى ، الإرسـال الذي لايمـر من بين الحبل والثبكة ولا تسقط على إحدى المنـاطق يعطى صفرا ،

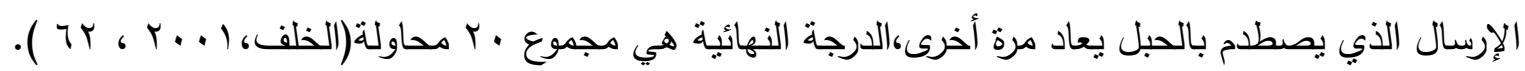

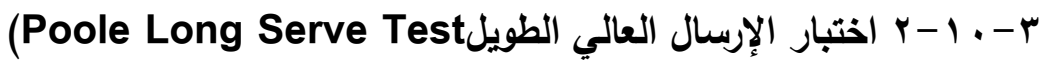
- هدف الاختبار : قياس دقة مهارة الإرسال العالي الطويل . - تطبيق الاختبار : طبق على عينة من طلاب المعاهد والكليات ولكلا الجنسين •

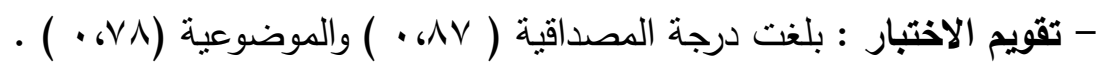

- الأدوات المطلوية : مضارب ريشة ، كرات ريشة الطائرة ،مساعد ،ملعب مخطط بتصميم الاختبار كما في الشكل

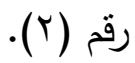

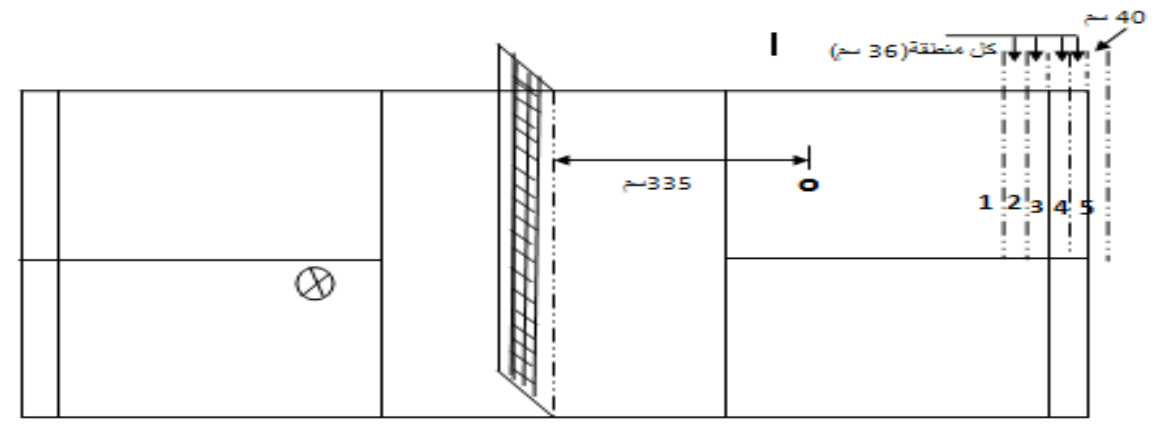

الشكل رقم (Y)يوضح ملعب الريشة الطائرة مخطط بتصميم اختبار الإرسال العالي الطويل

- طريقة تنفيذ الاختبار :

يقف اللاعب المرسل في المنطقة (×) ويقوم بالإرسال بشكل عال وطويل بحيث تعبر الريشة من فوق الشبكة

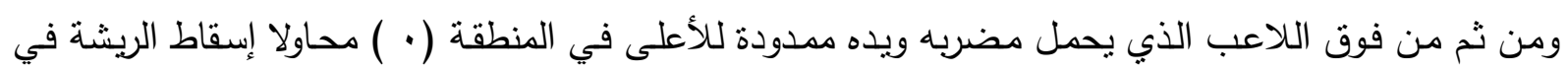
المنطقة ذات الدرجة الأعلى ، ويقوم بإرسال ( r I ) محاولة . - حساب النقاط : - تعطى الدرجة على وفق مكان سقوط الريشة . - الريشة التي تقع على خط بين منطقتين تعطى الدرجة الأعلى .

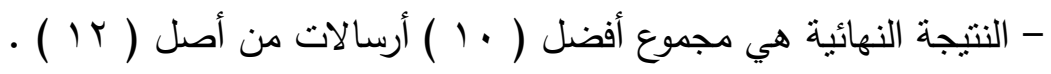

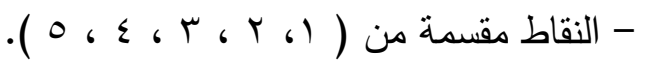

( Ray Collins \& Patrick Hadges:1978 Op.cit.P.48-51.)

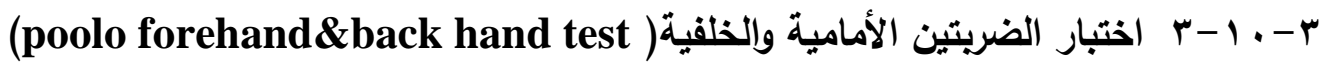
- هدف الاختبار : قياس الدقة في مهارة الضربة الأمامية والضربة الخلفية . - تطبيق الاختبار : طبق على عينة من طلاب المعاهد والكليات ولكلا الجنسين .

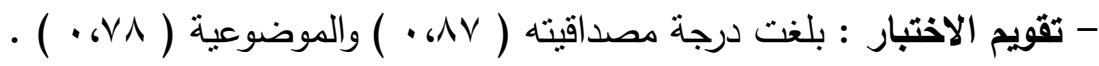

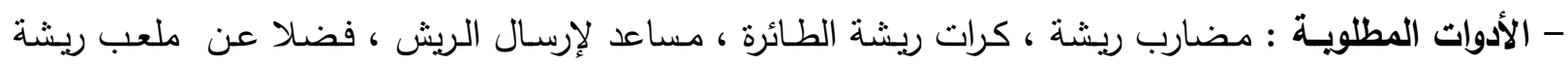
مخطط بتصميم الاختباركما في الثكل رقم(ب). 


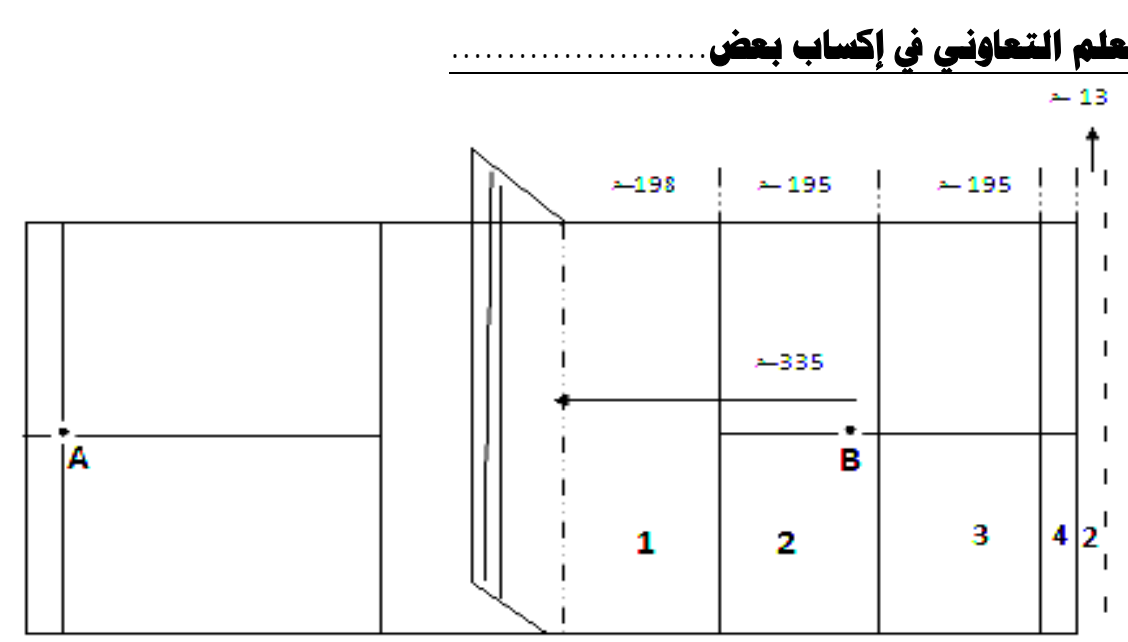

الثكل رقم (ب)يوضح ملعب الريشة الطائرة مخطط بتصميم اختبار الضريتين الأمامية والخلفية

طريقة تنفيذ الاختبار :

في الضربة الأمامية يقف اللاعب وقدمـه اليمنى على المربع (A) ومضربه بوضـع الضربة الأماميـة ،

ويقوم بضرب الريشة المرسلة إليه من الملعب المقابل ( B ) بقوس عال لتسقط قبل حدود الملعب الفردي بقليل وبشكل عمودي على سطح الملعب محاولا إسقاطها في المنطقة ذات الدرجة الأعلى التي هي مدرجة من (1) ل

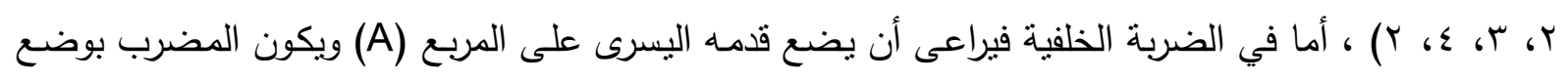
الضربة الخلفية ويتم إجراء الاختبار كما في الضربة الأمامية .

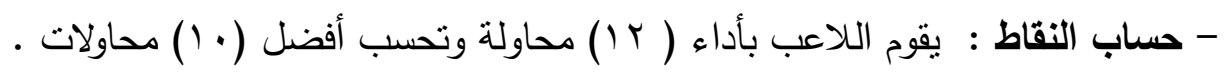
- تعطى الدرجة على وفق سقوط الريشة .

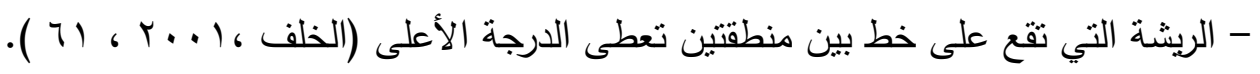
r- ب- 1- اختبار ضرية الإبعاد الافاعية ( French Clear Test): - هدف الاختبار : قياس الانجاز لمهارة ضربة الإبعاد الدفاعية . - تطبيق الاختبار : طبق على عينة من طلاب المعاهد والكليات ولكلا الجنسين . - تقويم الاختبار : بلغت درجة مصداقيته ( (010، . ) والموضوعية (91، . ) .

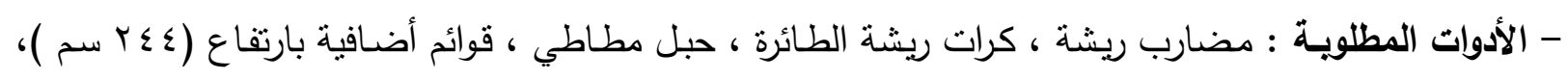
مساعد،ملعب ريشة مخطط بتصميم الاختبار كما في الثكل رقم (ع).

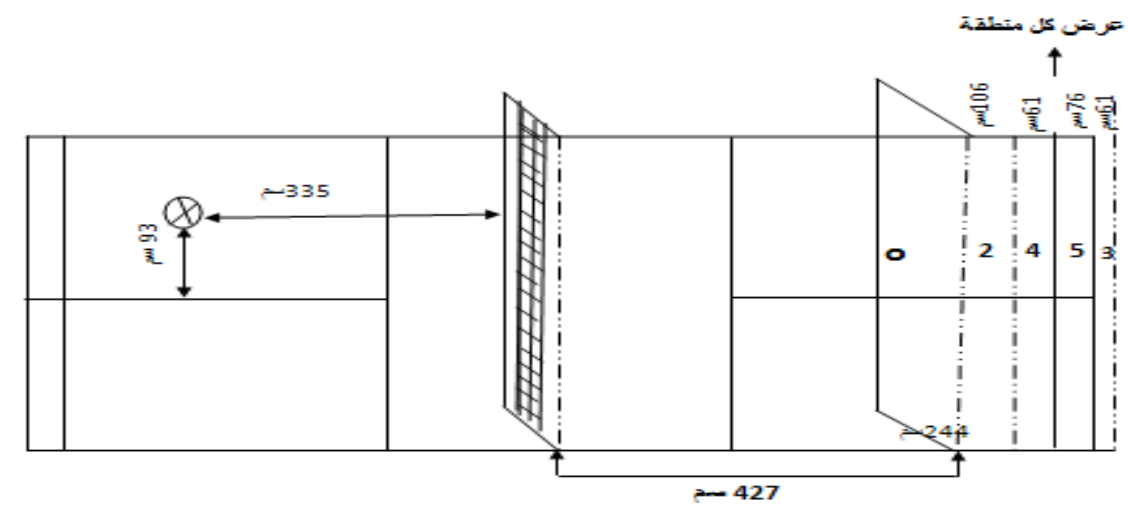

الثكل رقم (؛ ) يوضح ملعب الريشة الطائرة مخطط بتصميم اختبار ضرية الأبعاد الدفاعية 
- طريقة تنفيذ الاختبار : يقف اللاعب في المنطقة (× ) ويقوم برد الريشة المرسلة إليه من منطقة ( • على شكل ضربة أبعاد عالية للجهة المقابلة له ويشترط أن تمر من فوق الشبكة ومن ثم تعبر من فوق الحبل الذي

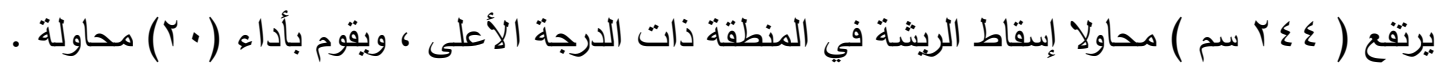

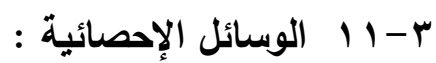
تمت معالجة البيانات الإحصائية بالحاسوب الآلي وباستخدام حزمة البرامج الإحصائية SPSS وتضمن

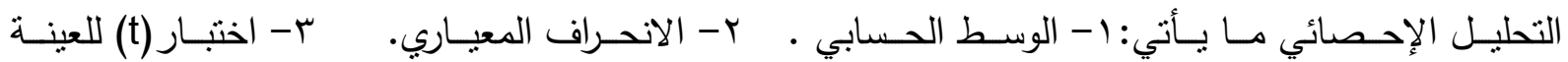

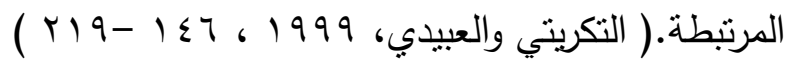

$$
\begin{aligned}
& \text { צ - عرض النتائج ومناقشتها : } \\
& \text { צ- - 1 عرض النتائج: }
\end{aligned}
$$

الجدول رقم(ץ) دلالة الفروق بين الاختبار القبلي والبعدي في بعض المهارات الأساسية للريشة الطائرة

\begin{tabular}{|c|c|c|c|c|c|}
\hline \multirow{2}{*}{ المحسوبة } & \multicolumn{2}{|c|}{ الاختبار ألبعدي } & \multicolumn{2}{|c|}{ الاختبار القبلي } & \multirow{2}{*}{ الأساسية } \\
\hline & $\varepsilon$ & س س & $\varepsilon$ & س - س & \\
\hline * & $\varepsilon$ ؛ $9 \cdot \varepsilon$ & 18.7 & r. r. & $\Lambda_{6} \vee V$ & الإرسال الطويل \\
\hline$* 9.01 \mathrm{~V}$ & 1.0 .9 & M.0 & $V_{6} \leqslant 0$ & 17.8 & الإرسال القصير \\
\hline$* \Lambda_{6} r V r$ & . . VTY & r Y & Y.01: & $1 r_{6} 9$ & الضربة الأمامية \\
\hline$* 0,197$ & $r_{6} \leqslant 17$ & rr & r.TrI & $1 \varepsilon$ & ضرية الإبعاد \\
\hline
\end{tabular}

للمجموعة التجريبية

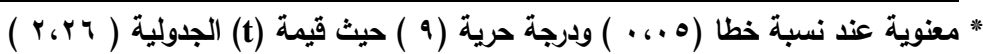

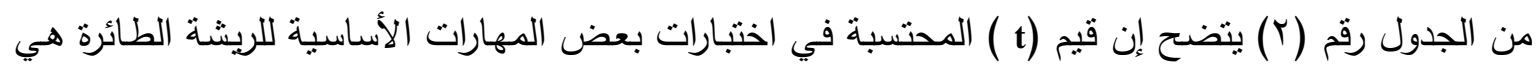

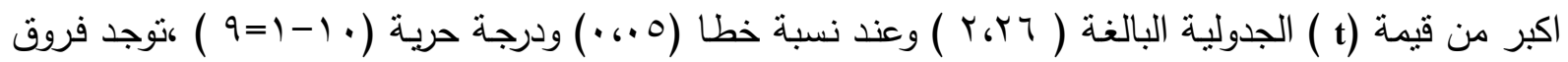
ذات دلالة معنوية في جميع الاختبارات ولمصلحة الاختبار ألبعدي • الجدول رقم(ץ) دلالة الفروق بين الاختبار القبلي والبعدي في بعض المهارات الأساسية للريشة الطائرة المجموعة

\begin{tabular}{|c|c|c|c|c|c|}
\hline \multirow{2}{*}{ قالمحسوبة } & \multicolumn{2}{|c|}{ الاختبار ألبعدي } & \multicolumn{2}{|c|}{ الاختبار القبلي } & \multirow{2}{*}{ الأسهاسية } \\
\hline & $\varepsilon$ & س - l - l & $\varepsilon$ & س - l - l & \\
\hline$* 9_{6} \diamond 9 \wedge$ & r.TVV & $1 r_{6} 0$ & $r_{6} \ldots r$ & 7.7 & الإرسال الطويل \\
\hline$* V_{6} \cdot \wedge r$ & $168 \cdot 7$ & $r ., 0$ & 9.179 & $1 \leqslant 69$ & الإرسال القصير \\
\hline$* 1.6100$ & $1670 \mathrm{~V}$ & Y1. T & \&,Vrr & $11, r$ & الضرية الأمامية \\
\hline$* 116 \leq 70$ & r.q9r & rA, $r$ & $7, \mathrm{TVA}$ & Tr.r & ضربة الإبعاد \\
\hline
\end{tabular}
الضابطة

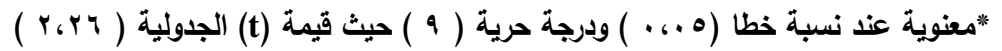

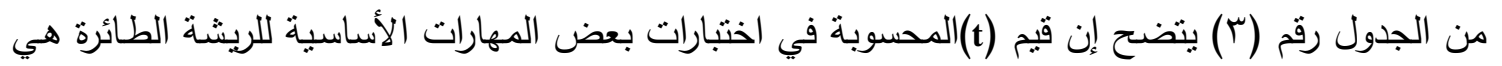

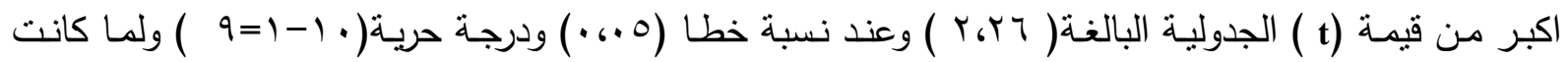


القيمة المحسوبة اكبر من الجدولية ، إذ وجدت فروق ذات دلالية معنوية في جميع الاختبارات ولمصلحة الاختبار

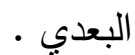
الجدول رقم (؛) دلالة القروق لاختبارات بعض المهارات الأساسية للريثة الطائرة لمجموعتي البحث في الاختبار ألبعدي

\begin{tabular}{|c|c|c|c|c|c|}
\hline \multirow{2}{*}{ قيمة T } & \multicolumn{2}{|c|}{ المجموعة الضابطة } & \multicolumn{2}{|c|}{ المجموعة التجريبية } & \multirow{2}{*}{ المهارات الأساسية } \\
\hline & $\varepsilon$ & س س & $\varepsilon$ & س س & \\
\hline *Y,rY & r.tVV & $1 \%, 0$ & $\varepsilon$ ؛ $9 . \&$ & $1 V . r$ & الإرسال الطويل \\
\hline *Y,o & 16.7 & $r .60$ & 1.0 .9 & $r 1, r$ & الإرسال القصير \\
\hline 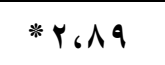 & $1.70 \mathrm{~V}$ & ri. & . & rr,A & الضرية الأمامية \\
\hline$* \varepsilon, r \cdot \xi$ & r.99r & $r \wedge, r$ & r.\&17 & rr & ضرية الإبعاد \\
\hline
\end{tabular}

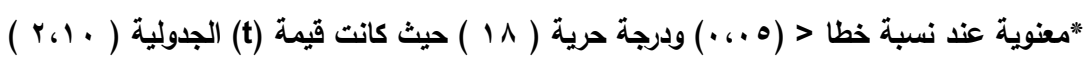

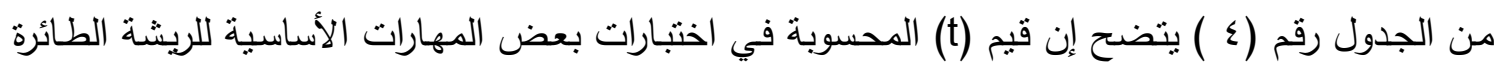

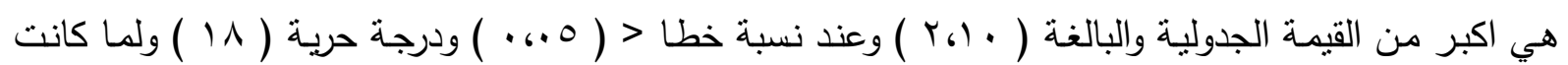

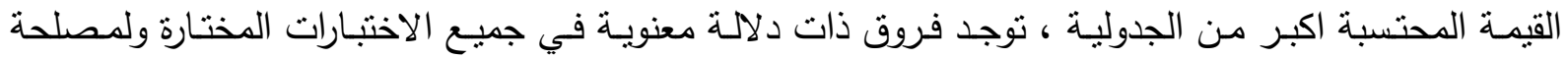

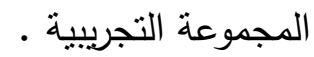
ع - r مناقثة النتائج: يتضح من خلال نتائج البحث المعروضة في الجدول ( r ، r ، ، ) ) وجود فروق ذات دلالة معنوية بين متوسطات درجات طلاب المجموعة التجريبية والضابطة ولمصلحة المجموعة التجرييية التي درست بطريقة التعلم التعاوني وقد حدث تعلم للمجموعتين ولكن مجموعة التعلم التعاوني تعلمت بشكل اكبر وذلك لاستثار زمن تكرار

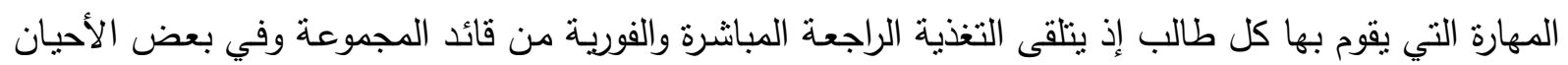
من مدرس المادة ، وعلى عكس المجموعة ذات التعلم التقليدي إذ ينتظر الطالب فترة زمنية لكي ينلقى التغذية التهاية

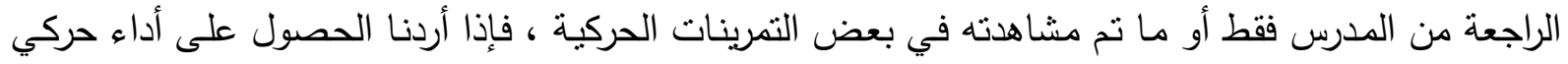

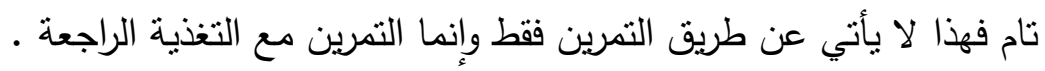

(ع7، (عنمان (1917)

لذا فان أسلوب التعلم التعاوني يجعل من عدد محاولات تتفيذ التمرين الواحد اقل نسبيا من طريقة التعلم

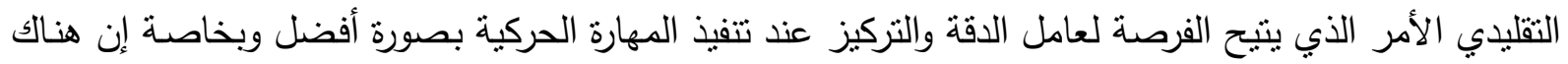

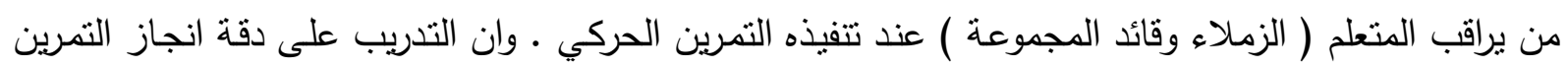

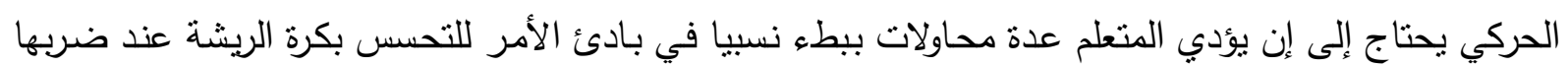

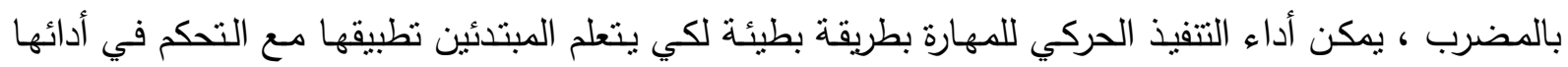

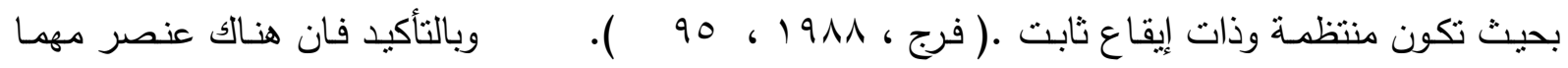

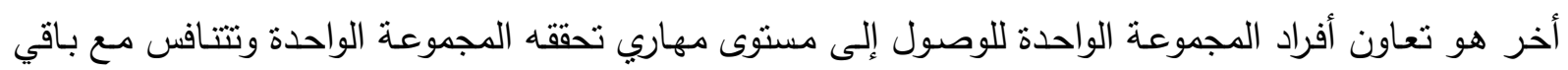

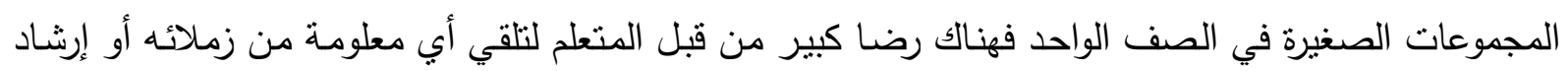

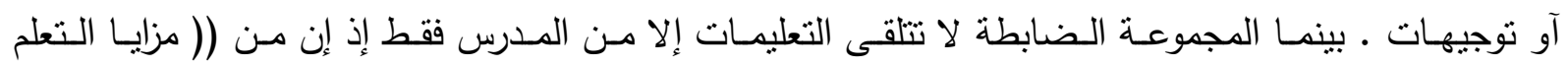

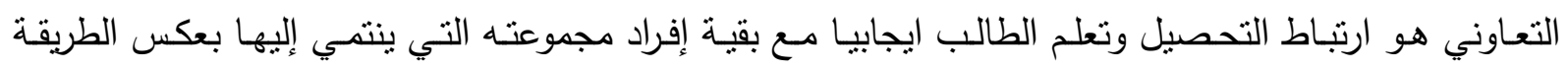




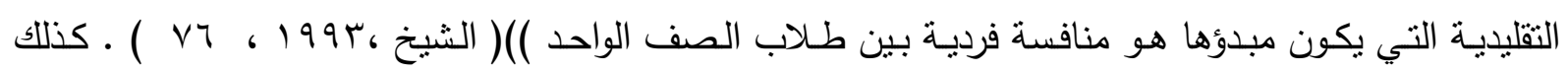

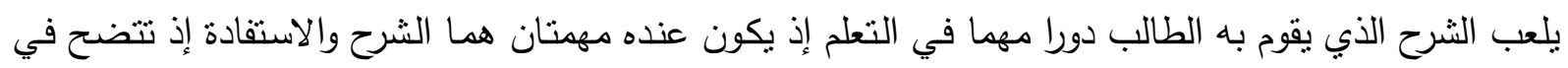

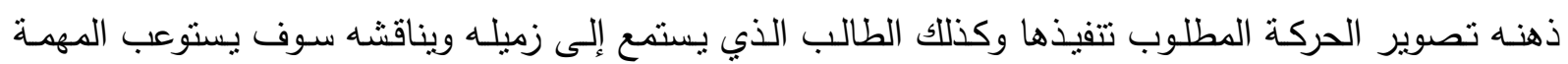

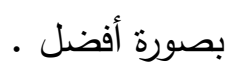

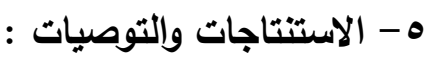

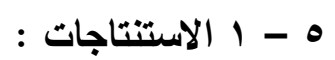

1 - أثتنت النتائج إن استخدام أسلوب التعلم التعاوني ذو فاعلية في إكساب وتعلم بعض المهارات الأساسية للعبة

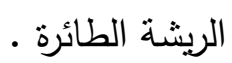
r - كان تحصيل نتائج اختبارات الطلاب الذين تعلموا على وفق أسلوب التعلم التعاوني( المجموعة التجريبية)

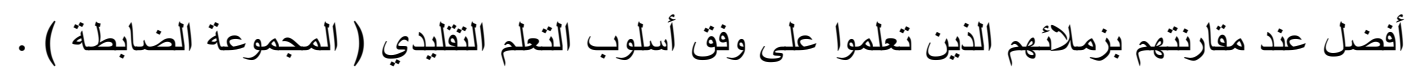

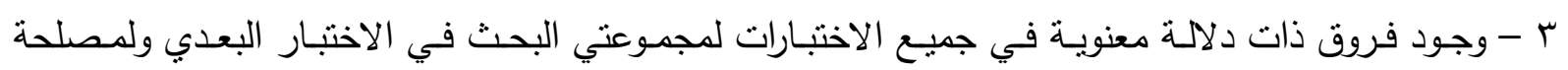
المجموعة التجريبية.

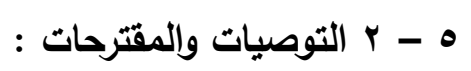

1- التأكيد على استخدام أسلوب التعلم التعاوني في إكساب وتعلم بعض المهارات الأساسية للعبة الريثة الطائرة

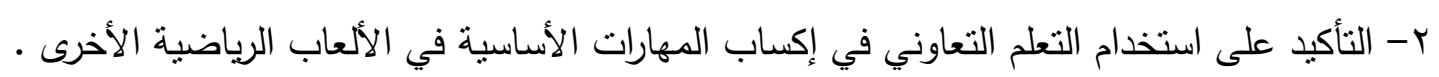

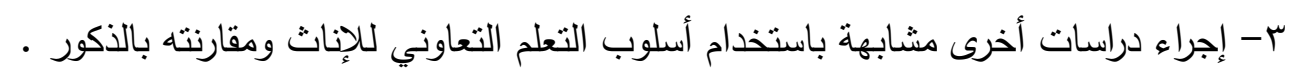

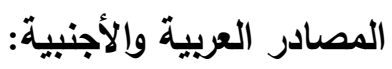
الاطوي ،وليد وعد الله (991 (191) :اثر التعلم التعاوني في تحقيق الأهداف التعليمية لفعالية التس الأرضي،

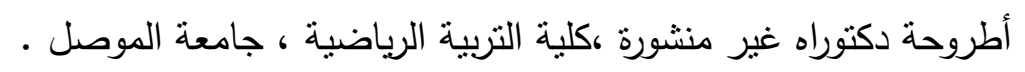

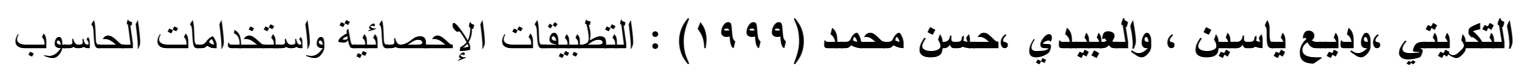
في بحوث التربية الرياضية ،دار الكتب للطباعة والنشر ،جامعة الموصل.

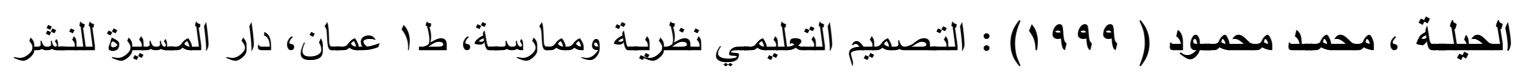
والتوزيع والطباعة.

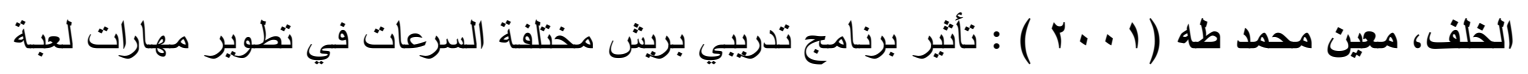

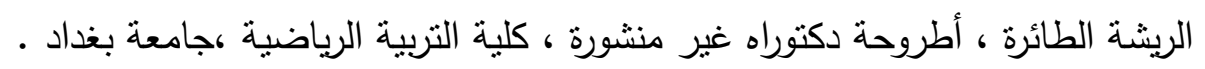

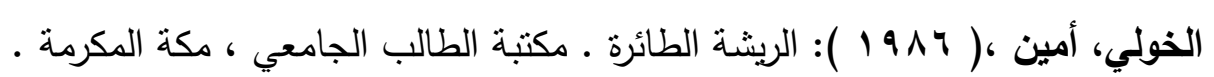

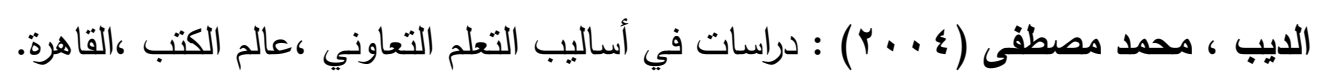

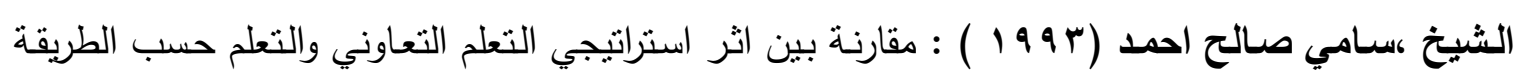

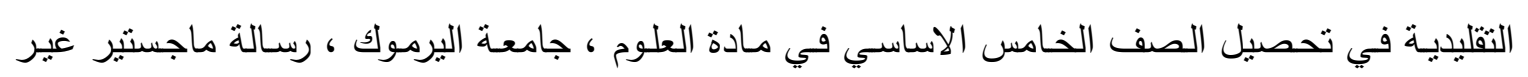
منشورة . عثمان ،محمد عبد الغني (19AvV) : (1991) : التعلم الحركي والتدريب الرياضي ، ط1 ، دار القلم ،الكويت.

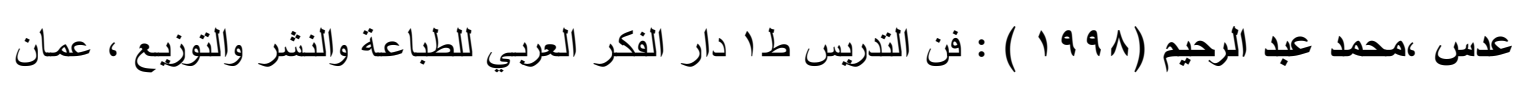
• الأردن 
• فرج، عنايات محمد أحمد ( $19 \wedge \wedge$ ) : مناهج وطرائق التدريس في التربية الرياضية الحديثة ، دار الكتب الجامعية ، الإسكندرية

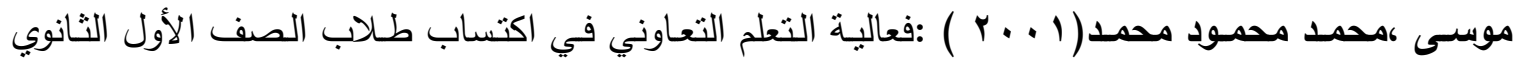
لمهارات القراءة الناقدة ، الجمعية المصرية للمناهج وطرق التدريس ، دراسات في المناهج وطرق التدريس ، العدد V V

- Bo omose Gaard (1996) :Phvsical Training for Badminton .In ternationl Badminton Federation . England-

- JaKe,Downey . ( 1976) Teach Your child Badminton . Lapus BooK

- John Edwards Cro wood (1997): sports-Badminton-The cro wood presslt UK.

- Mathews DK(1978): Measus ment in physical Education ed ,Philadelphia W.B-samudersco-

- Peter Roper(1995) : The skills of the Games Badminton - UK - .

- Ray Collins \& Patrick Hodges ( 1978) : A Comprehensive Guide to Sports Skills Tests and Measurement. Charles Thomas Publishers.USA.

الملحق رقم ( ) أسماء الخبراء لتحديد أهم المهارات الأساسية بالريشة الطائرة

\begin{tabular}{|c|c|c|}
\hline 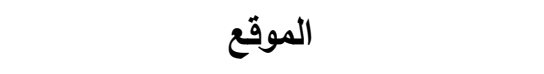 & 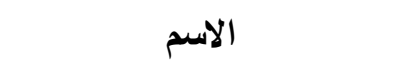 & $ت$ \\
\hline جامعة الموصل / كلية التربية الرياضية & أ.م.د سبهان محمود الزهيري & 1 \\
\hline جامعة الموصل / كلية التربية الرياضية & م وليد ذنون يونس & r \\
\hline جامعة الموصل / كلية التربية الرياضية & م • عمار محمد خليل & $r$ \\
\hline جامعة الموصل / كلية التربية الرياضية & م مم عمر فاروق يونس & $\varepsilon$ \\
\hline
\end{tabular}

نموذج لوحدة تعليمية بأسلوب التعلم التعاوني

(خطة تدريسية مقترحة بأسلوب التعلم التعاوني)

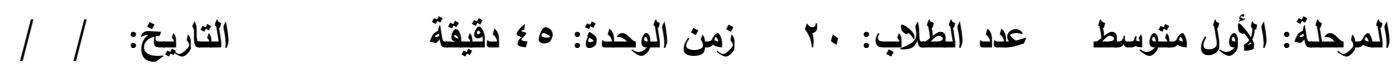

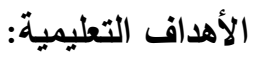

ا ـ إن يؤدي الطالب الإرسال العالي الطويل بالريشة الطائرة " 
أثر استخدام التعلم التعاوني في إكساب بعض

\begin{tabular}{|c|c|c|c|}
\hline إحماء عام للجسم مع تمارين خاصة بالمهارة & ه ادقيقة & التمريناتة الإحماء & |الإعدادي \\
\hline 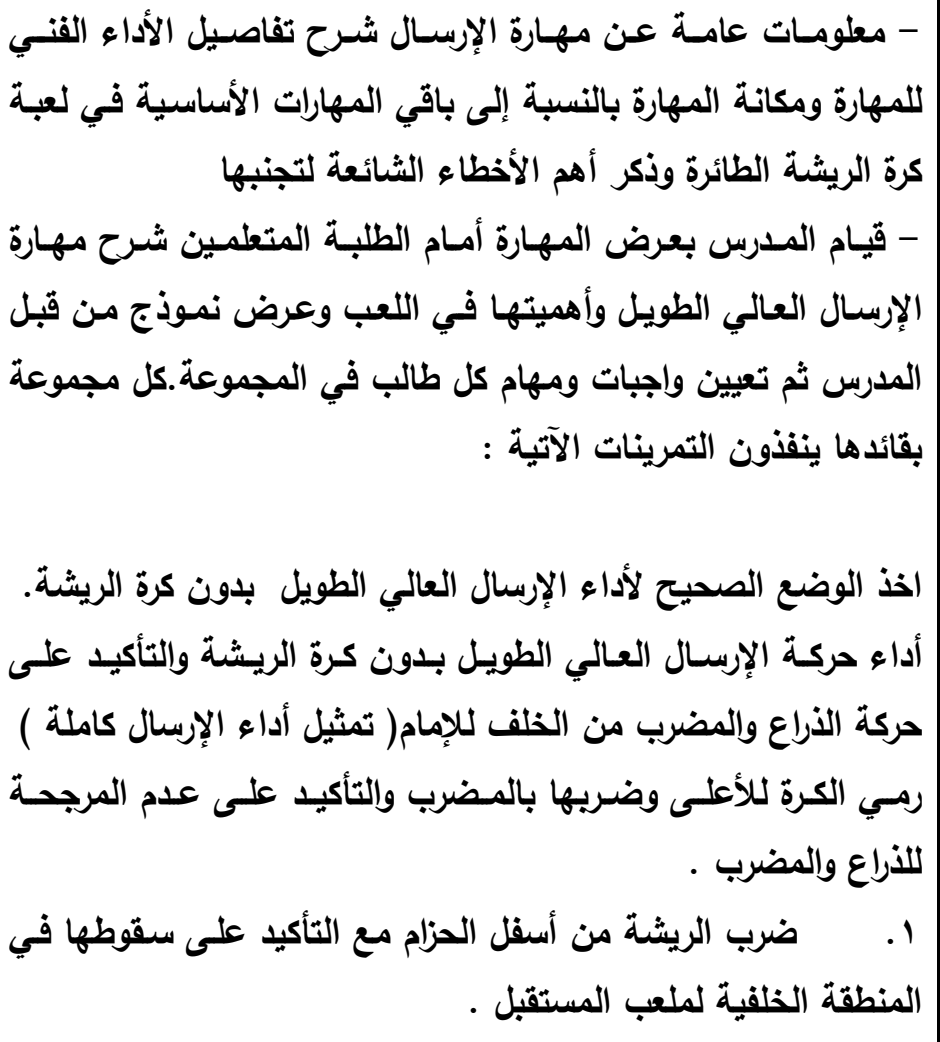 & 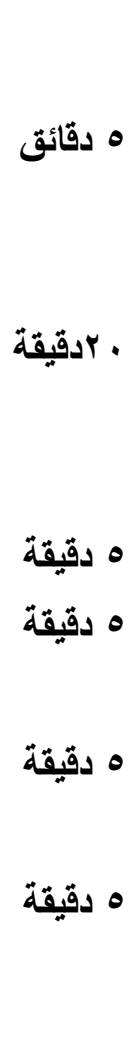 & الجزء التعليمي & |القسم الرئيسي \\
\hline إعطاء واجب تحضيري للارس القادم مع تمرينات تهائـة وإسترخاء ثم & ه دقائق & & \\
\hline
\end{tabular}

